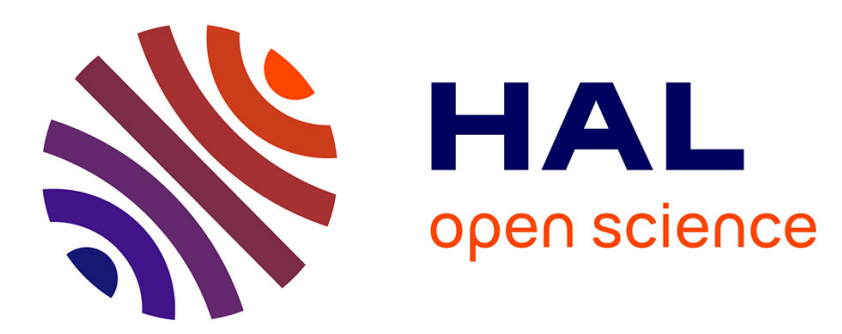

\title{
Dynamical models of biomarkers and clinical progression for personalized medicine: The HIV context
}

\author{
R Thiébaut, Mélanie Prague, D Commenges
}

\section{To cite this version:}

R Thiébaut, Mélanie Prague, D Commenges. Dynamical models of biomarkers and clinical progression for personalized medicine: The HIV context. Advanced Drug Delivery Reviews, 2013, 65, pp.954 965. 10.1016/j.addr.2013.04.004 . hal-00933761v2

\section{HAL Id: hal-00933761 \\ https://hal.inria.fr/hal-00933761v2}

Submitted on 31 Aug 2017

HAL is a multi-disciplinary open access archive for the deposit and dissemination of scientific research documents, whether they are published or not. The documents may come from teaching and research institutions in France or abroad, or from public or private research centers.
L'archive ouverte pluridisciplinaire HAL, est destinée au dépôt et à la diffusion de documents scientifiques de niveau recherche, publiés ou non, émanant des établissements d'enseignement et de recherche français ou étrangers, des laboratoires publics ou privés. 


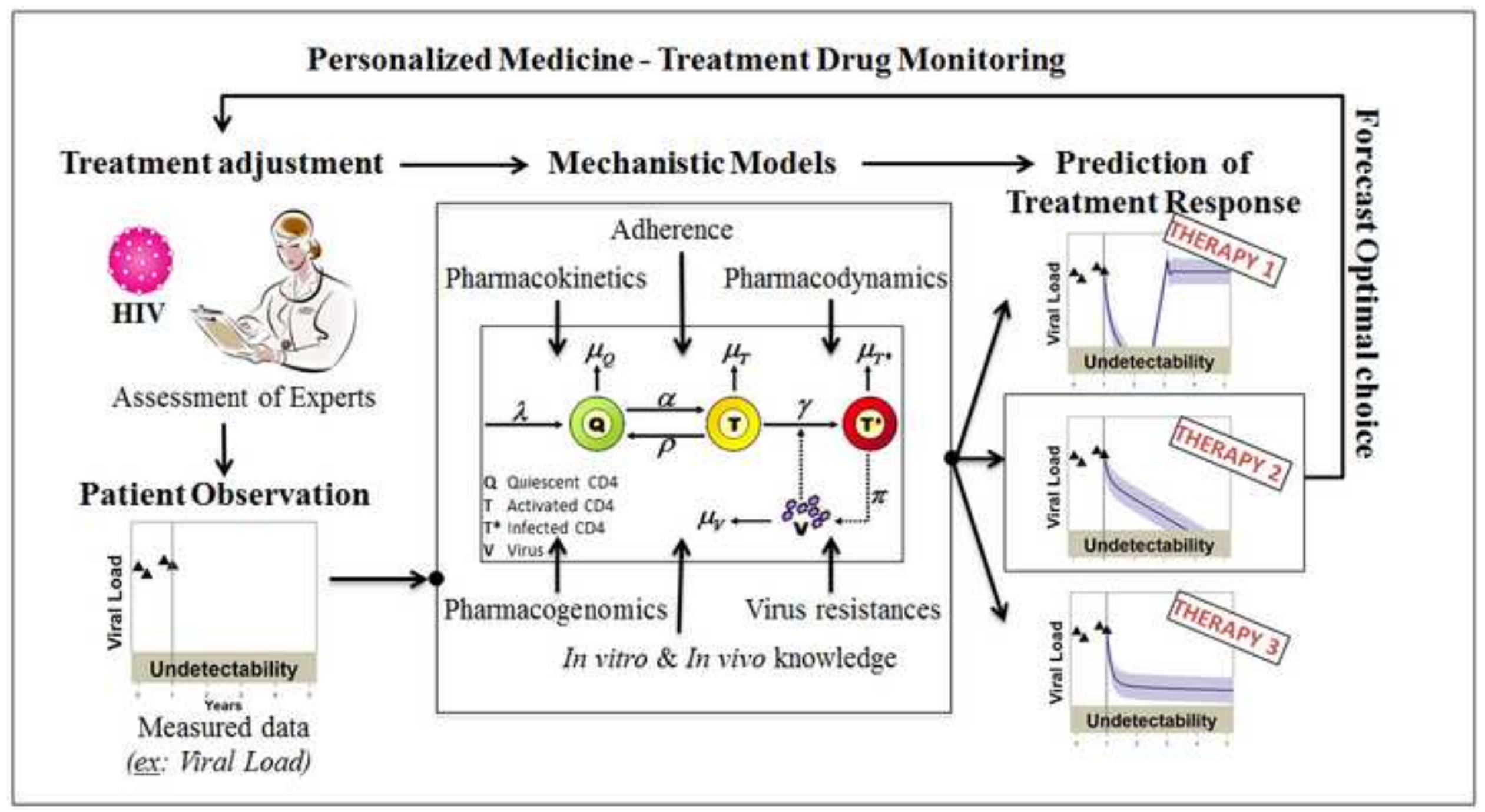




\title{
Dynamical models of biomarkers and clinical progression for personalized medicine: the HIV context
}

\author{
R. Thiébaut*, M. Prague and D. Commenges \\ University of Bordeaux, ISPED-Epidémiologie-Biostatistique, F-33000 Bordeaux, France \\ INSERM, ISPED, Centre INSERM U897, F-33000 Bordeaux, France \\ *corresponding author: Tel +33557574521 email: rodolphe.thiebaut@isped.u-bordeaux2.fr \\ Received 15 December 2012.
}

\begin{abstract}
Mechanistic models, based on ordinary differential equation systems, can show very good predictive capacities that will be useful to build treatment monitoring strategies. In this review, we present the potential and the limitations of such models for guiding treatment (monitoring and optimizing) in HIV-infected patients. In the context of antiretroviral therapy, several biological processes should be considered in addition to the interaction between the viral and the host immune systems: the mechanisms of action of the drugs, their pharmacokinetics and pharmacodynamics, as well as the viral and host characteristics. Another important aspect to take into account is clinical progression, although its implementation in such modelling approaches is not easy. Finally, the control theory and the use of intrinsic proprieties of mechanistic models make them very relevant for dynamic treatment adaptation. Their implementation would nevertheless require their evaluation through clinical trials.
\end{abstract}

Key words: Mechanistic models, dynamic models, personalized medicine, HIV infection, biomarkers

\section{Content}

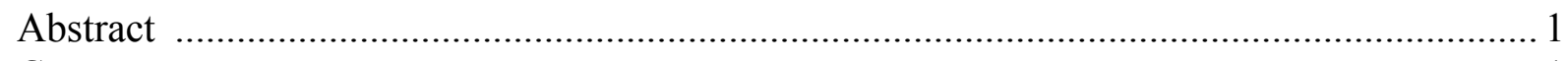

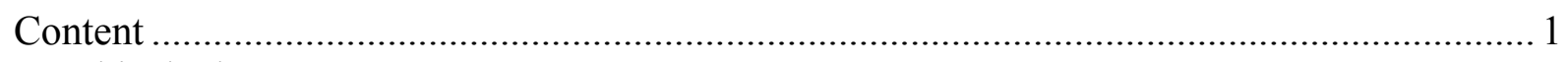

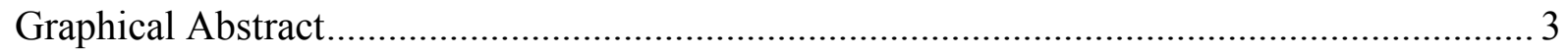

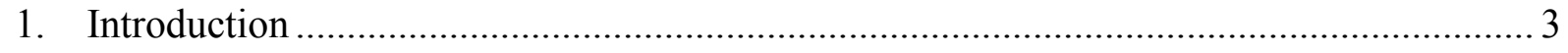

2. Models for HIV biomarker dynamics and their predictive ability. ............................... 4

2.1. A tool: the dynamical/mechanistic models ................................................................ 4

2.2. An example of field of application: HIV infection ........................................................ 5

2.3. Predictive ability of the "activated cell" model in HIV infection..................................... 8

3. Including in vivo/in vitro drug efficacy and compliance ............................................. 10

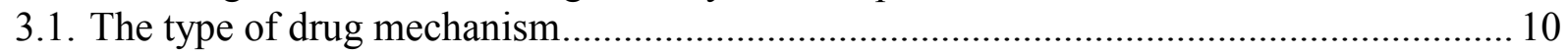

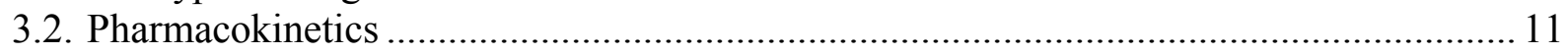

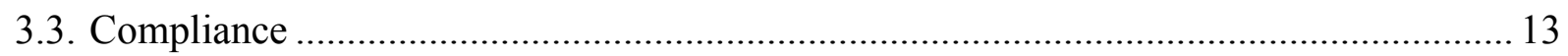




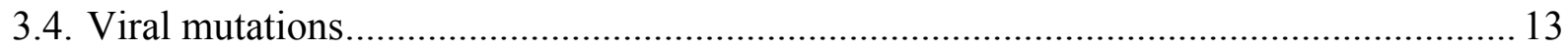

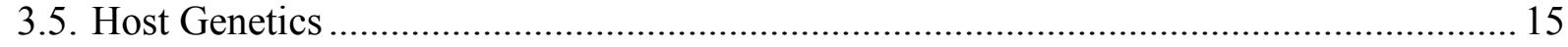

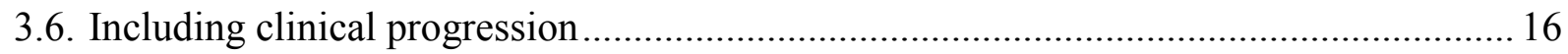

4. Toward the use of mechanistic models for personalized medicine .................................. 17

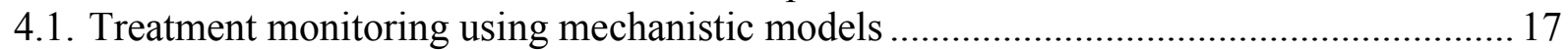

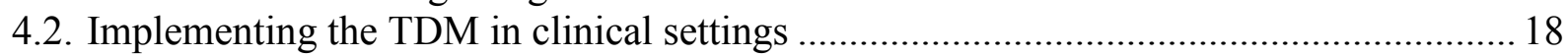

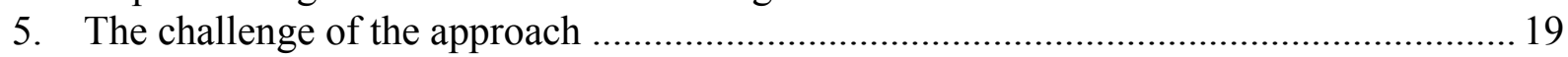

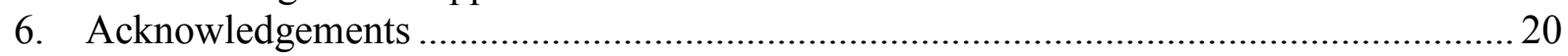

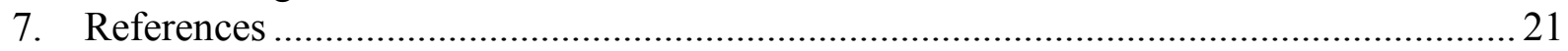

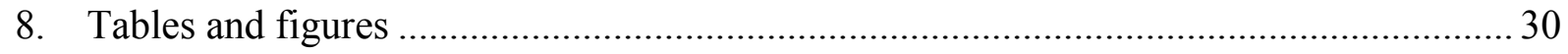

Abbreviations: Human Immunodeficiency Virus (HIV); Highly active antiretroviral Therapy (HAART); Therapeutic Drug monitoring (TDM); Structured Treatment Interruptions (STI); Ordinary Differential Equation (ODE); Pharmacokinetics (PK); Pharmacodynamics (PD); Pharmacogenomics (PG) 


\section{Graphical Abstract}

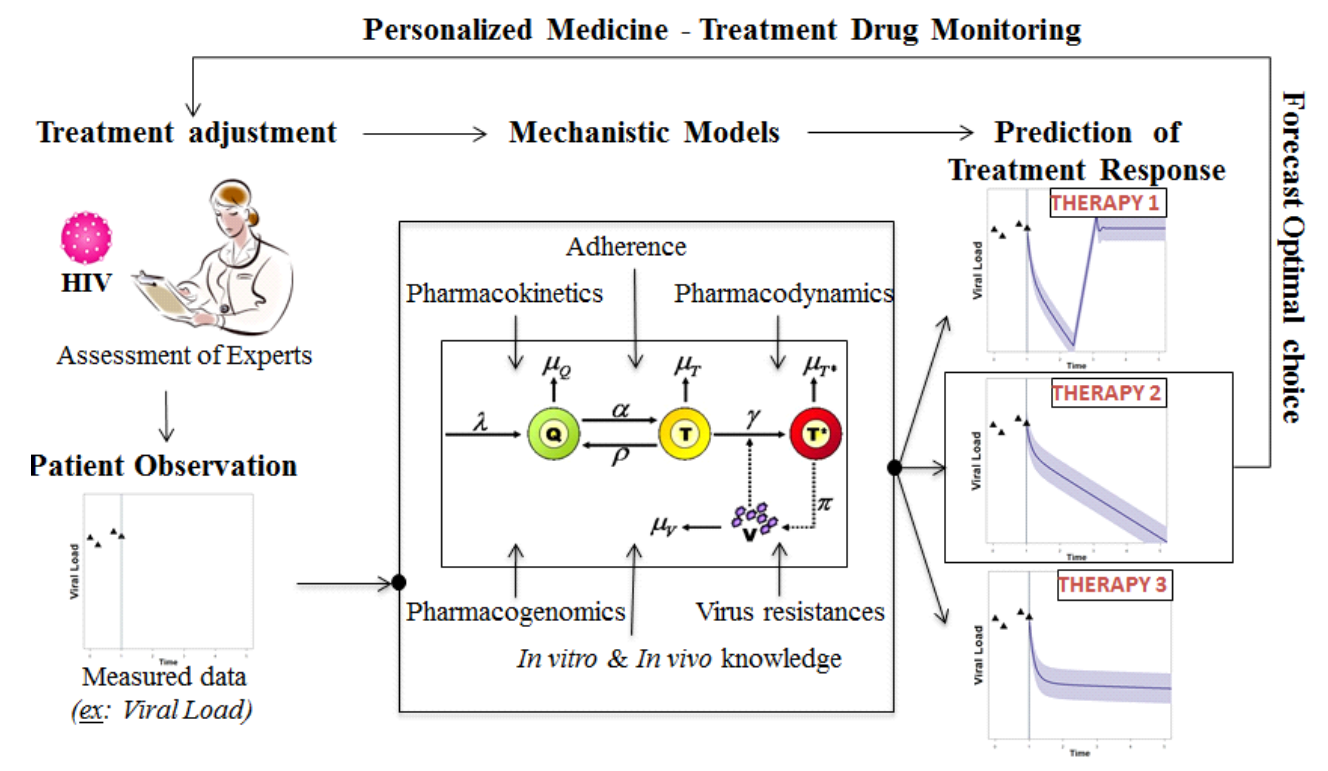

\section{Introduction}

Guidelines for medical treatments are usually based on empirical results of clinical trials. For instance, for defining the treatment of an HIV infected subject, these recommendations pertain to four questions [1] : when to start antiretroviral therapy? What to start? When to change? What to change?

The guidelines are defined at a population level and are to be applied to all patients in a standardized way. Personalized medicine aims at defining more specific criteria for each patient. A usual approach is to define subgroups that would more likely benefit from starting or changing a treatment than others because of some individual characteristics based on clinical, biological or genetic markers. Once the treatment is started, another possibility is to observe the initial response of a given patient in order to adapt his/her treatment dynamically: this is often referred to as Treatment Drug Monitoring (TDM) or adaptive treatment strategy ([2]-[4]). Although mathematical models could be useful for this purpose, their use is actually limited by the complexity of their implementation. A well known example is the regulation of insulin injection based on glycaemia measurements [5]. In a model-based approach, the idea is to learn from the data collected from an individual to forecast the best choices likely to procure the best clinical outcomes. This relies on considering the patient as a "system" that is changing over time ([2], [6] and [7]). It then becomes possible to apply models to regulate this 
system and thereby achieve more desirable outcomes based on control of the input and feedback [8].

The main objective of this review is to show how useful mechanistic models can be for personalized medicine, with a special emphasis on HIV infection. This is introduced in Section 2, where we also present a model of HIV dynamics which has already proven its predictive ability. In Section 3, we then review the potential of using additional information relating to the individual's clinical data related to the HIV infection such as patient's compliance, pharmacokinetics/dynamics data, viral and host genetics. In section 4 we discuss attempts that have been made for treatment monitoring and the challenges that remain to be addressed.

\section{Models for HIV biomarker dynamics and their predictive ability.}

\subsection{A tool: the dynamical/mechanistic models}

In medicine and especially in clinical research, mathematical models can be useful for dealing with the growing amount of information. More and more factors are recorded for each patient, and more and more biomarkers are measured repeatedly over time. The aim of modelling is usually to summarise multi-dimensional datasets, as well as trying to predict outcomes in future patients. A summary may be a set of independent factors associated to the occurrence of a disease, such as in traditional epidemiological studies. Regarding models, two types can be distinguished, i.e. 'descriptive' and 'mechanistic' models. Descriptive models are designed using a standard structure that will best fit all available data, with a view to capture association between factors and the evolution of the disease. For instance, if a continuous marker is repeatedly measured over time and has a non-linear evolution, a model based on non-linear mixed effect could then be used. Once the estimates have been obtained, the interpretation of the results might then lead to biological hypotheses explaining the link between factors and the change in the marker. In contrast, the "mechanistic" approach starts from biological knowledge. Biological knowledge is translated into a set of mathematical equations, generally a system of differential equations. Here, we will restrict our discussion to the case of ordinary differential equations (ODE), although models have also been based on the more complex partial differential equations or stochastic differential equations. The ODE system defines a dynamical system for which the behaviour can be studied. There generally are, however, several unknown parameters involved in such a system of differential equations, 
and its behaviour will of course depend on the value of all parameters, including the unknown ones.

Mechanistic models based on differential equations are commonly used in physics. Using this type of models in biology is challenging because the biological mechanisms are different from physical laws and the biological systems are generally more complex than physical systems. In other words, models are always a simplification of reality, but an acceptable simplification is often more difficult to achieve in biology than in physics. The gap between model and reality may be reduced by increasing the model's complexity, or by introducing stochasticity [9]. Moreover, in physics many parameters are assumed to be known while in biological models, nearly all the parameters are either estimated, or unknown. Thus, the issue of parameter estimation, which is a statistical issue, is a major challenge in biological models. As a consequence, in order to be able to estimate the parameters, a compromise has to be found to design a reasonably simple model which correctly fits the observed data, an issue coined in statistics as the parsimony principle. In mechanistic models we have the additional requirement that the structure of the model must represent important characteristics of the underlying biological mechanisms.

Using a mechanistic model presents the advantage of bringing external information to the analysis, i.e. information coming from the knowledge of the biological mechanisms at work, which may lead to a comparison of models reflecting different biological mechanisms [10]. Interaction between various biomarkers may be better captured by the mechanistic modelling than by a complex descriptive model. For instance, several descriptive models were suggested for jointly modelling two markers in HIV infection such as viral load and lymphocytes $\mathrm{T}$ $\mathrm{CD} 4{ }^{+}$count ([11]-[14]). However, none were fully satisfactory because none gave both a good fit of the data and an easy biological interpretation of the parameters.

The mechanistic nature of the model should ensure two fundamental properties: i) the parameters should be universal (at least approximately) in the sense that their value should be consistent across any datasets (e.g. cell survival rate); ii) the predictive ability should be better than that of a descriptive model, that is in situations with data different from those used for learning the model. Once a model has been obtained and shown to have a good predictive ability, it becomes possible to envisage using it for controlling the response, for example for adapting and monitoring drug treatments.

\subsection{An example of field of application: HIV infection}


The HIV infection provides a good example of the use of mathematical mechanistic modelling. The basic biological knowledge is as follows. The HIV virus uses the CD4 receptor to enter into a cell that it will infect: thus the target cells are those presenting a large number of $\mathrm{CD} 4$ receptors, essentially the $\mathrm{CD}^{+} \mathrm{T}$ lymphocytes. It is the use of mechanistic models that helped to reveal that a high turn-over of virus and cells is a fundamental phenomenon in the HIV disease [21].

When infected subjects are given a potent antiretroviral drug, the viral load decreases sharply. Assuming there is no more viral replication, the half-life of the virus can be estimated by fitting a simple exponential model (which is the solution of the differential equation $\frac{d v}{d t}=-\mu_{V} V$, where $\mu_{V}$ is the viral load). Further refinements provided updated estimations of the infected cells half-life [15]. This revealed that the half-life of the virus was short [16]. Hence, the equilibrium state observed during the asymptomatic phase of the HIV disease was actually associated to a constant renewing of both the virus and target cells with a very high turnover rate. One implication of these results was the very high probability of mutations of the virus in just one day. This understanding constituted one of the bases for the rationale of combined antiretroviral therapies that is now the standard of care. These models, as any model, made several strong assumptions, including a perfect efficacy of the antiretroviral treatment (see [17], [18] for a review). This assumption was acceptable as a first approximation because the antiretroviral treatments were highly potent on a short term. However, researchers have also used these models to estimate the antiviral potency of the antiretroviral regimen [19]. Although this objective is clinically highly relevant, several methodological issues arise when embarking in such studies. This is presented in part in the Wu's paper of the present issue (see [20] in this journal) and summarized in the following paragraphs.

A wide variety of models exists. As mentioned above, in the pioneering work of Wei et al. [16], only the viral decay was modelled. A model that also incorporated viral production with separate analysis of the viral load and CD4 count was then developed [21]. Later, many proposals were made by various authors, leading to models including more compartments. First, distinguishing between uninfected and infected CD4+ T lymphocytes (in short "CD4") led to detect that there are heterogeneous half-lives for infected cells and that more complex nonlinear models are needed to accurately describe long-term viral decay ([15], [22]). Several other models were then proposed, assuming exponential life-span of infected CD4 [23], different maturation stages of CD4, CD8 modelling [24] and mutations, most of the time 
modelled by a finite number of mutants in a discrete form ([25]-[27]). Most of these models were associated to new breakthroughs in the understanding of the infection, and were designed to include the action of antiretroviral drugs. The effects of different drug classes, however, have typically been aggregated in these modelling approaches, with some notable exceptions ([19], [28]-[30]).

Nevertheless, most of these works are burdened by problems of identifiability: see [31], [32] for a description of this issue in the HIV setting. One of the main problems is that, while it is useful to distinguish several types of cells, leading to several compartments, only very few compartments can be observed clinically (typically two in the HIV setting: CD4 count and viral load). Because of the difficulty of estimating parameters, most authors used mathematical modelling as a tool for studying possible dynamics of the system when all the parameters are fixed in advance. With carefully chosen values of parameters, this type of approach can indeed be valuable, for example to examine hypotheses on different biological mechanisms [33], to perform simulations of mutations occurrence [34], to compare designs of therapies ([30], [35]). In a particularly interesting instance, Smith and Wahl proposed an impulsive differential equations model accounting for kinetics of drug actions to evaluate the effect of the duration of the interval between administrations [30]. It was found that a high frequency and a short interval dosing interval is compulsory to maintain a "normal" $\mathrm{T}$ cell count and a threshold defined per individual can result in optimized dosing intervals. However the behaviour of dynamical systems strongly depends on the values of the parameters. This type of approach is thus limited to an exploratory phase.

We believe that the strength of the mechanistic models approach for medicine individualization can be exploited only if the parameters have been estimated from data. Estimation is a statistical problem, and this represents a particularly challenging one for mechanistic models. A proposed solution to the problems related to identifiability, is to fit the model not on a single patient but using a sample of patients. However, the assumption that the parameters are the same for all patients does not hold. Treating some parameters as random allows taking into account inter-patient variability. Statistical approaches using random effect models have been developed and applied to data from large clinical trials samples. One should note, however, that fitting ODE-based models with random effects is numerically challenging (see [36] for a review and [37]-[41] among others for original developments). 


\subsection{Predictive ability of the "activated cell" model in HIV infection}

In this section, we illustrate the good predictive ability that can be achieved with a particular mathematical model applied to a HIV clinical trial. We used the data of the controlled randomized open-label ALBI ANRS 070 trial [42] in which three antiretroviral strategies based on two nucleosidic reverse transcriptase inhibitors (NRTI) were compared in 151 previously untreated patients over 24 weeks. The 51 patients from arm 1 received the d4T (stavudine) + ddI (didanosine) treatment, with drug doses adjusted to their weight: $\mathrm{d} 4 \mathrm{~T}$ $250 \mathrm{mg}$ plus ddI $60 \mathrm{mg}$ for patients under $60 \mathrm{~kg}$, and d4T 400mg plus ddI $80 \mathrm{mg}$ for those above $60 \mathrm{~kg}$. For arm 2, 51 patients received $500 \mathrm{mg}$ of zidovudine (AZT) and $300 \mathrm{mg}$ of lamivudine (3TC). In the third arm (49 patients), patients were given the same treatment as in arm $1(\mathrm{D} 4 \mathrm{~T}+\mathrm{ddI})$ for 12 weeks and then switched to the treatment given to arm 2 patients $(\mathrm{AZT}+3 \mathrm{TC})$ for the remaining 12 weeks. CD4 counts and viral loads were measured every 4 weeks until 24 weeks. Two patients dropped out before the time of the first blood sample collection, so 149 patients were available for the Intent-To-Treat analysis (ITT). For each patient, changes in dose were either self-reported or declared by the clinician. The details of the design and the collecting methods have been described in details elsewhere [42].

The "activated cell" model is represented by a four-dimensional ODE system, featuring quiescent $(\mathrm{Q})$ and activated $(\mathrm{T})$ uninfected CD4+ T cells, infected CD4+ T cells $\left(\mathrm{T}^{*}\right)$ and viruses (V) concentrations (see Figure 1 and Error! Reference source not found. for parameters description):

$$
\left\{\begin{array}{l}
\frac{\mathrm{dQ}}{\mathrm{dt}}=\lambda+\rho \mathrm{T}-\alpha \mathrm{Q}-\mu_{\mathrm{Q}} \mathrm{Q} \\
\frac{\mathrm{dT}}{\mathrm{dt}}=\alpha \mathrm{Q}-\gamma \mathrm{VT}-\rho \mathrm{T}-\mu_{\mathrm{T}} \mathrm{Q} \\
\frac{\mathrm{dT}}{\mathrm{dt}}=\gamma \mathrm{VT}-\mu_{\mathrm{T}^{*}} \mathrm{~T}^{*}, \\
\frac{\mathrm{dV}}{\mathrm{dt}}=\pi \mathrm{T}^{*}-\mu_{\mathrm{V}} \mathrm{V} .
\end{array}\right.
$$

To take inter-patient variability into account, parameters can be modelled as the sum of a population (fixed) parameter $\tilde{\theta}_{0}$ and a random effect $b_{i}$ having independent standard normal distributions: $\tilde{\theta}_{\mathrm{i}}=\tilde{\theta}_{0}+\mathrm{b}_{\mathrm{i}}$ leading to a mixed effects model. After a forward selection strategy [43], parameters $\tilde{\alpha}, \tilde{\lambda}$ and $\tilde{\mu}_{\mathrm{T} *}$ were found to vary substantially among patients and were selected for having random effects, while the other parameters were assumed constant in the 
population. Because the antiretroviral drugs considered were inhibitors of the reverse transcriptase, the treatment was assumed to act on the infectivity parameter $\gamma$ [44]. For a specific treatment, the standardized dose $d$ (smoothed over three times, $100 \%$ if full-dose, the percentage of the drug intake otherwise) was introduced as covariate with a power function $\mathrm{\kappa}$ and infectivity depended on treatment effects $\beta$ as follows: $\tilde{\gamma}_{i}=\tilde{\gamma}_{0}+\beta \mathrm{d}^{\kappa}$. This can be easily extended to treatment regimens by considering as many treatment effects and power functions as the number of drugs in combination.

Although the model distinguishes between quiescent, non-infected and infected CD4, only the total number of CD4 is observed. We built an observational model for the $\log _{10}$ of the viral load and the fourth root of total CD4 count (written $\left.\mathrm{Y}=\left[\log 10(\mathrm{~V}),\left(\mathrm{Q}+\mathrm{T}+\mathrm{T}^{*}\right) 0.25\right]\right)$ plus a measurement error that we assumed Gaussian with standard deviation. A method for parameters estimation based on penalized maximum likelihood can be found in [39] and it has been implemented in the NIMROD program (Normal approximation Inference in Models with Random effects based on Ordinary Differential equations) which is available for download [45]. The penalized likelihood approach can be thought of as an approximate Bayesian approach: the approximation consists in approximating the posterior distribution of the parameter by a normal distribution (which is asymptotically justified). Other software programs are available for fitting such models [46].

From the ALBI data, we constructed a training dataset for estimating the model parameters and a validation dataset on which we performed predictions. To avoid over-fitting, we excluded the patients for whom we made predictions from the learning set. A description of the analysis can be found in [47]. The individual predicted trajectories of viral load and CD4 count were computed by plugging individual estimates of parameters into the ODE model and by computing the solutions numerically.

We assessed two endpoints: prediction of treatment changes and dose changes. In the third arm of ALBI, patients switched treatment after 12 weeks. To examine whether it was possible to forecast their response to the new treatment given during the remaining 12 weeks, we selected patients at each decile of the distribution of HIV viral load at the end of the study and excluded them from the learning dataset. For each patient belonging to these different deciles, we used the first 12 weeks associated with the first 4 measurements to compute individual parameters and predict the patient's response to the treatment modification. Figure 2 presents the individual prediction of the markers for a patient (the median patient for viral load) who 
switched from $\mathrm{d} 4 \mathrm{t}+\mathrm{ddI}$ to $\mathrm{AZT}+3 \mathrm{TC}$. The predictions thus obtained were quite good: only $4.9 \%$ of the observations were out of the $95 \%$ measurement error predictive intervals. This high quality of prediction suggests that this arm could actually have theoretically been avoided since we were able to predict the marker dynamics reliably for each individual. The same type of analysis was performed to assess the predictive abilities of our models to dose changes. In spite of a rough function linking the dose and the effect, predictions of the response to treatment changes were also found to be quite good (

Figure 3 and Figure 4a). Taken together, Figure 4a and Figure 4b illustrate that, as expected, these predictions are better if many observations from the patients are used to build the predictions. In other words, short-term predictions are better than long-term predictions. In this particular example, CD4 counts can be correctly predicted using three patients' observations of biomarkers (both viral load and CD4 count), whereas one is not sufficient.

It should be recognized that the quality of these predictions is also linked to the most likely hypothesis that the AZT $+3 \mathrm{TC}$ regimen has a lower potency in this trial. Indeed, the prescribed AZT dose of $300 \mathrm{mg} / \mathrm{d}$ was probably too low if we consider that the current dose prescribed nowadays is $600 \mathrm{mg} / \mathrm{d}$. Albeit, additional virus genotype data did not allow to conclude for a higher incidence of resistance mutations in AZT+3TC group [48].

In conclusion, the individual predictions of the mechanistic model in this trial were found to be very good, thanks to the relevance of the model used in this application and a full estimation of all the parameters jointly. If the mechanistic model does not include a biological mechanism playing an important role in a given circumstance, however, the predictions will probably not be as good as those we observed in the ALBI trial. Further work is currently ongoing to look at the robustness of such models with more up to date antiretroviral therapies. Moreover, since it is generally accepted that this kind of model is by definition missspecified, other components will have to be considered to go further.

\section{Including in vivo/in vitro drug efficacy and compliance}

\subsection{The type of drug mechanism}

A potential power of mechanistic models is to distinguish between the mechanisms of action of different antiretroviral agents. Nowadays, five classes of antiretroviral agents exist which do not act on the same pathways (see [49] for a review). Entry inhibitors, interfere with the binding, fusion and entry of the HIV virus. Reverse transcriptase inhibitors (RTIs) impair the synthesis of the HIV DNA genome from the RNA strands. In mechanistic models, we may 
consider that drugs belonging to these two classes decrease the rate of infection of the CD4. Consequently, infectivity parameter $(\gamma)$ or analogue should be reduced. Integrase inhibitors block the action of the integrase, a viral enzyme that inserts the viral genome into the cell nucleus. Different stages of infection of the CD4 cells can be modelled, the last stage being virus production. Thus, integrase inhibitors diminish the rate of conversion from early stage infection to late-stage infection. It has been argued that the steep viral load decrease observed with integrase inhibitors is due to the action of the drug at a rather late stage of the viral life cycle [29]. Finally, Protease Inhibitors (PIs) prevent the viral replication by inhibiting the activity of proteases enzymes used by the virus to cleave nascent proteins for the final assembly of new virions. This can be represented in the model by assuming that part of the produced viruses are defective and non-infectious [50]. Altogether, antiretroviral drugs do not act at the same stage of the viral life cycle; this has a significant impact on the dynamics of the system and must be adequately represented in the models developed. Of note, the ability to distinguish the biological mechanism of any antiretroviral drug will depend on the precision of the measurement (e.g. infected cell, integrated DNA...). In this regard, the models used in most previously published studies have assumed known and/or constant effects of the drugs ([50]-[52]).

\subsection{Pharmacokinetics}

Pharmacokinetics (PK) of antiretroviral drugs are also important factors, but they are difficult to use directly because of the high variability between subjects in the drugs' absorption, distribution, metabolism and excretion [53]. Moreover, bioavailability and protein binding can complicate the drugs' quantification in vitro and cause confusions [54]. Although the antiretroviral activity should be linked with plasma concentration (PK), this is only ever a correlation with the drugs' intracellular concentrations, which are the truly significant variable [55]; this is mainly because antiretroviral agents act mostly at intracellular sites. Quantification techniques thus need to improve before PK values can be used reliably to evaluate treatment efficacy and clinical endpoints. Thus, the PK data may be insufficient to guide the adjustment of administered doses in patients appropriately and must be combined with considerations about pharmacodynamics (PD).

Several factors are important to determine PK-PD relations, ranging from inter-patients differences to heterogeneity of viral responses to drugs, as well as interactions between the 
two. Error! Reference source not found. presents a summary of some of the most used indicators. Most of the time, PD is evaluated in vitro since it is easier to measure viral replication in the presence of various concentrations of the drug. The most commonly used indicator is the IC50, defined as the concentration of drug required to achieve $50 \%$ inhibition for a specific strain of virus. This is a static indicator that does not indicate what the impact of lower or higher drug concentrations would be. Moreover, it is a poor reflection of antiviral activity since it depends on the intrinsic properties of the drug, the kinetics of the stage of the viral life cycle and the kinetics of the infected cells [17]. Inhibitory Quotients (IQs) are associated with the virological response since they are defined as the ratio between drug concentration ( $C_{\text {through }}$, plasma concentration before the next dose) and IC50 [56]. IQs are, however, also constant factors and do not describe dynamic variations according to the administrated doses. Hence, using dose-response curves from infectivity assays has been suggested for quantifying the antiretroviral potency [57]. The Instantaneous Inhibitory Potential (IIP) is a function of the dose $(D)$. It is dynamic thanks to the Hill coefficient $(m)$ that is the slope of the dose-response curve. This is particularly interesting because it allows to use the number of infected cells as a direct readout for viral replication. In practical terms, IIP is the logarithm of the number of single-round infection events reduced by a drug [58]:

$\operatorname{IIP}(D)=\log _{10}\left(1+\left(\frac{D}{\operatorname{IC5} 50}\right)^{m}\right)$

Thus, the effectiveness of an antiretroviral in vivo is determined by $m$ and IC50. It then becomes possible to introduce time variations by using the PK for a particular dosing schedule leading to $D(t)$ (where $t$ is the time). This time-varying ratio between the dose and IC50 in IIP has an interpretation comparable to IQs [58]. Moreover, apart from the dynamical advantages, IIPs are similar to IQs for predicting HIV responses to antiretroviral agents [59]. Furthermore, IIPs are sensitive to PK-boosting effects and interactions between drugs [60]. Empirically observed interactions of antiretroviral drugs in clinical trials are reviewed in [61]. There is no metric to describe the combined effect of multiple drugs, but, four categories of interactions can be distinguished: synergism when one drug enhances the effect of the other; Bliss independence when each drug inhibits a portion of the targets; Loewe additivity that assumes that two inhibitors act on a target through a similar mechanism; and antagonism when action of a drug inhibit the action of the other [62]. Combined IIP can be evaluated in vitro and reflects these interactions. An exhaustive listing for more than 166 pair-wise and 1892 three-ways combinations over 20 treatments is available in [63]. This provides a large 
dataset of in vitro potency assessment and a quantitative basis to compare and analyse treatment effects.

However, extrapolating from in vitro data to in vivo situations is complex. First, in vitro susceptibility assays do not follow the viral dynamics during days or weeks but at a specific time point in specific conditions [64]. Second, variations of several fold of these PK-PD indicators can occur during particular clinical situations such as acute infections, advanced HIV disease or pregnancy [65]. This can, however, be partially corrected by introducing explanatory variables, or by introducing a conversion parameter that has to be estimated from the data [66]. This is analogous to introducing a scaling factor that is reflective of the uncertainty between the drug measurements of drug potency in vitro and the specific modelbased drug potency in vivo [67] .

\subsection{Compliance}

Compliance to treatment is essential for achieving efficient concentration at the target tissues. Lack of compliance can be represented by dose-delay or dose-omission. Although many methods exist, adherence remains very difficult to assess [68]. Poor compliance is a key factor for explaining viral load variations and is strongly associated with treatment failure ([69], [70]) as it favours viral mutations and therefore viral resistance to treatment (see next section). Nevertheless, the impact of compliance varies according to the type of antiretroviral regimen [71]. For estimation concerns, poor or unmeasured compliance can result in an underestimation of drug effectiveness leading to overestimation of drug dosage [72]. A classical and convenient way to take compliance into account in models is to include a compliance rate $A(t)$ and to replace the dose $D(t)$ by the product $A(t) D(t)$ in the PD model ([38] and [73]-[77]).

\subsection{Viral mutations}

Genotypic and phenotypic characteristics of the virus can also greatly influence the response to antiretroviral treatment. Genetic barrier for resistance refers to the number of nucleotide changes a virus needs to accumulate to become resistant to a given antiretroviral drug. Information on patterns of resistances and cross-resistances is important for making decisions on how to change and combine drugs to achieve an optimum antiviral effect. Hence, genotype 
information is increasingly used for deciding which antiretroviral drugs should be included in a given regimen.

Genotypic and phenotypic assays based either on the detection of specific point mutations or on complete DNA sequencing are increasingly available [78]. In vitro assessment of HIV fitness has been extensively studied by different techniques; see [79] for a complete review of this topic. In short, resistance is typically measured by the virtual phenotype which is the fold change in IC50 relative to the Wild-Type (WT) virus ([80], [81]). A derivation of this is the virtual Inhibitory Quotient (vIQ), which is the IQ divided by the virtual phenotype and has been shown to have a significant link with the viral response to treatment [82]. An improvement is to introduce vIQs in IIPs (described in Section 2.1 multiplying the IC50 by the virtual phenotype leading to virtual IIPs) because this allows accounting for the steepness of the dose-response curves (represented by Hill coefficient $m$ ). This is particularly important for PIs whose IC50 is usually the same in mutant variants and WT but for which a higher dose is needed to achieve viral extinction because $m$ is smaller [83]. In vivo, the viral response to a new antiretroviral regimen is studied according to the genotype measured at the time of treatment change. Various approaches have been proposed to predict the response to antiretroviral regimen according to the baseline genotype [84].

In mathematical modelling, mutations are introduced by adding virus compartments to account for different strains of virus (for an example, see the pioneering work of Nowak et al. [85]). One approach consists in considering that several genotypes of the virus, $V=\left(V_{l} \ldots V_{K}\right)$ exist in each patient. They are called quasi-species. The different genotypes may have different fitness, which is efficiency of replication. In real life, the number of genotypes can be large, but numerical complexity limits the number of possible genotypes that can be represented in a model [86]. Another approach which is easier to build focuses on vIIPs instead of IIPs, and modulates the treatment effect depending on the mutant variant $\mathrm{k}$. ODE-based models with immune cells and multiple strains of viruses have allowed the comparison of scenarios; as an example of results, it has been calculated that the probability that resistant mutants pre-exist to treatment is higher than the probability that resistant mutants are generated during therapy [87]. In similar models, Rong et al. introduced the effects of compliance to short-term [77] and long-term [88] treatment, and showed that many variants of the virus live as quasi-species in the host. Mutant variants that are selected have a lower sensitivity to the antiretroviral drugs and are associated with a rebound of the viral load [89]. The resistant viruses are capable of replicating better than the sensitive viruses and will 
therefore be positively selected [90]. The viral fitness of a mutant is, however, generally lower than that of a wild type; consequently, replication, virulence, and transmission of the selected mutant viruses may be reduced compared with those of the wild-type [91]. Specific models have been suggested for estimating these differences in viral fitness ([92], [93]).

An integrated model has been recently proposed by Rosenbloom et al. [76]. The authors suggested that this type of approach might be more relevant for the evaluation of the likelihood of reaching a good antiviral response than the use of a genotype because this latter information is based on meta-analysis of data obtained from various regimens in patients with various characteristics. However, the effect of mutations is probably highly dependent on this context according to the results. In practice the detection of resistant mutants is commonly used to choose or modify the drug regimen given to a patient but this kind of knowledge has not yet been incorporated in a mechanistic model for personalized medicine.

\subsection{Host Genetics}

It is not common to use pharmacogenomic (PG), that is the patients' genetic data, for determining the choice of antiretroviral drug but this may be relevant in some very specific indications. For instance, the HLA-B*5701 allele has been shown to lead to a risk of about $50 \%$ of hypersensitivity with abacavir, making the screening of this haplotype systematic before prescribing this drug [94]. Drug-drug interactions and genetic polymorphism in drugmetabolizing enzymes and drug transporters (MDR1, CYP3A5, CYP2C19...) contribute to wide variability in drug pharmacokinetics, response to therapy and toxicity ([95]-[98]). For instance, using a population pharmacokinetics model including genetic characteristics, several CYP2B6 polymorphisms have been identified as being associated with steady-state nevirapine clearance among HIV-infected patients [99]. A dynamic approach is valuable to model gene interaction in a quantitative manner [100]. A modelling strategy with linear ODEs has been proposed by $\mathrm{Lu}$ et al. to capture gene regulatory network [101]. The perspective to introduce biomarkers and antiretroviral drugs as new compartments in these systems is appealing and can bridge the gap to combine PK-PD-PG to explain HIV dynamics under treatment. To date, however, the information on individual susceptibility to antiretroviral drugs remains sparse [96]. The inclusion of any PG data in mechanistic models, provided that the information is available, can be expressed by modelling some parameters as a function of individual values. The remaining inter-individual variability is then taken into account through random effects on parameters, especially those representing treatment effects. 
Including PG information would decrease the unexplained variability captured by the variance of the random effect.

\subsection{Including clinical progression}

The first outcome of interest when modelling the response to antiretroviral treatment is the viral rebound [76] followed by the CD4 dynamics since both these markers are very good prognostic markers ([102], [103]). These markers, however, are still imperfect surrogate markers of clinical outcome, that is, it is not possible to predict the exact clinical effect of an antiretroviral treatment by just observing an increase in CD4 or a decrease of HIV viral load ([104], [105]). This is even more the case nowadays because AIDS-classifying diseases are less common, whereas the proportion of deaths due to cardiovascular diseases and cancer is growing [106]. Also, depending on the type of therapeutic approach used, the ability of these markers to reflect the clinical benefit is not guaranteed. For instance, the administration of the IL-2 cytokine results in a substantial increase of CD4 but without any significant clinical benefit [107].

Therefore, it may be important to model the dynamics of biomarkers and clinical progression jointly. Many joint models have been proposed in the literature, including applications in the HIV-AIDS field ([13], [14] and [108]-[111]). Wu et al. [112] proposed a joint model including a non-linear (bi-exponential) mixed effect model for the viral dynamics with a proportional hazards model for the time-to-disease progression, and a complete mechanistic model based on ODE including a time-to-event process has subsequently been proposed by Guedj et al. [113]. Starting from a previous ODE-based model [39], the time-to-disease progression has been linked to the marker's predictions at any time by a proportional hazard model. Such joint models of longitudinal markers and time-to-event processes take into account the informative missing data process due to the censoring of observations after the occurrence of disease progression. Furthermore, an easier two steps approach, where the longitudinal model is fitted first and predictions are then used in a survival model, ignores the variability of the parameters of the longitudinal model estimated in the first step [109]. Finally, in the context of adaptive treatment, one needs dynamical models from which predictions are available at any time, thus requiring joint models.

What is interesting with such models is that one can obtain predictions of changes in markers (CD4 count, viral load) but also the probability of disease progression (according to the change in markers). A treatment monitoring based on this type of models sounds very useful. 
However, the wide spectrum of clinical diseases observed today in HIV-infected patients is due to various processes, from antiretroviral side effects [114] to the consequences of longterm HIV infection (cell activation, inflammation) [115]. Therefore, including all types of clinical events may result in a highly complex model. On the other hand, this type of model could be devoted to specific questions. For instance, with the objective of finding an optimal dose of antiretroviral, a model that includes the effect on the viral dynamics as well as the probability of side effects could serve at finding a good compromise between viral efficacy and side effects.

\section{Toward the use of mechanistic models for personalized medicine}

\subsection{Treatment monitoring using mechanistic models}

HAART succeeds in reducing viral load in most HIV infected patients but does not eradicate the virus. Thus the treatment has to be taken life-long. To reduce the burden of side effects it has been proposed to interrupt the treatment under certain conditions or to find an optimal dose. Structured Treatment Interruptions (STI), where antiretroviral treatments are stopped either during a given period or according to CD4 counts has been a first attempt to optimize drug administration ([28], [116] and [117]). These periods of treatment interruption were supposed to boost the immune system, to offer pill burden vacancy and decrease side effects. Some studies have also evaluated strategies where the immune system was boosted with vaccine and/or interleukin (IL2) before interruption ([118], [119]). Unfortunately, the evaluation of the effect of STI on clinical outcomes through randomized clinical trials have concluded that STI were harmful [120]. Control theory (taken from engineering literature) has been suggested to find the optimal interventions that reduce a given cost function [121]. Quadratic cost functions that weighted system response (viral load or CD4 count)) and sideeffects of the drug have been proposed [9]. Although conceptually interesting, this approach is not realistic because i) the model is not known, ii) the choice of the cost function is debatable, iii) the treatment cannot be continuously adapted. More recent approaches tend to get free from cost functions [122] and do not aim at adapting the dose continuously [123]. Prague et al. [47] proposed to give the lowest dose for which there is infection control. This is based on ODE stability criterion, the reproductive number $\mathrm{R}_{0}$ also used in SIR models: if $\mathrm{R}_{0}<1$ there is extinction of the infection. Thus the idea is to give the lowest possible dose that ensures $\mathrm{R}_{0}<1$. Such an approach was applied to the ALBI clinical trial. The patients in the most potent group $(\mathrm{d} 4 \mathrm{~T}+\mathrm{ddI})$ were selected to evaluate the best dose change required. A specific patient with 
undetectable viral load (below 50 copies $/ \mathrm{mL}$ ) during all the study after treatment initiation was proposed a dose reduction up to $53 \%$ of his initial dose whereas another patient with default in infection control during antiretroviral therapy was assigned a moderate dose increase. Then, if we observe how the patient reacts to the new dose it should be possible to update it in an iterative manner. In Figure 5, this kind of adaptive treatment strategy is illustrated by a feedback loop where patients go iteratively through two steps: observation then adaptation of their treatment. Such recommendations should be tested in order to be validated and in order to observe how patients react.

\subsection{Implementing the TDM in clinical settings}

Before the efficiency of TDM on HIV disease control can be tested, a first step should be to assess the capacity of TDM to influence the concentrations of drugs or biomarkers values into a predefined range so as to validate or invalidate the model used, and the TDM approach. This could initially be applied to all antiviral drugs, with a view to focus subsequently on more "targetable" drugs. This was already done by Duval et al. [124], who showed that, among PIs, dose TDM is more likely to be useful for indinavir and lopinavir than for nelfinavir. Variability should also exist between treatment regimens: on this subject, Back et al. argue in favour of TDM for PIs instead of NRTIs [125].

It is still difficult to build an acceptable design to test TDM. To date, TDM trials are complex to interpret and statistically underpowered [126]. The method of choice would be a randomized clinical trial comparing at least two strategies: standard of care (SOC) and TDM. A flow chart, Figure 5, describes the general design. Primary and secondary end-points will have to be carefully chosen with a good metric to assess TDM success or failure. Moreover, three outcomes are to be assessed: safety, efficacy and cost-effectiveness. Concerning safety toxicity and tolerability, the trial must include intermediate analyses so as to stop the trial in case of harmful results, see STI trials as an example [120]. Evaluation of efficacy regarding impact on viral load and CD4 count is not sufficient, to assess long-term validity of the TDM we see as compulsory to evaluate the emergence of viral mutation and recommend a longfollow-up of patients after stopping the treatment adaptation strategies. Finally, costeffectiveness should be considered in case of superiority proof of TDM against SOC because the higher frequency of biological observations and medical visits is to put in perspective with a substantial benefit of TDM.

It exists illustrations of the design we presented: one of the simplest treatment adaptations in HIV infection is based on the use of viral resistance information. Several randomized clinical 
trials have been performed to evaluate a strategy based on resistance information compared to standard of care ([127]-[129]). Specific designs could, however, be considered for the evaluation of more complex approaches for dynamic treatment. Murphy [130] advocated for the use of adaptive design, where the term "adaptive" refers to the experimental design that could be flexible: changing strategy allocation according to the responses in previous patients. An example of this, he proposed is the sequential multiple assignment randomized (SMAR) trials where each individual may be randomized multiple times and multiple randomizations occur sequentially through time.

Finally, an easily acceptable way of testing, which can be adapted retrospectively by adjusting on confounders, should be to analyse a previously designed clinical trial in two groups: after the forecast of the best treatment according to mechanistic models, comparing results between patients who had treatments below TDM targets and others. This kind of comparison was partly used by Best et al. [131] to assess antiviral drug dose TDM and this study showed that patients below TDM forecast tended toward a greater viral load.

\section{The challenge of the approach}

In this paper, we have shown that, in HIV patients, mechanistic models could be very useful to perform individual prediction of the response to an intervention based on antiretroviral drugs and could therefore be a useful tool for treatment monitoring. This could also be the case for other interventions such as immune based therapy ([119], [132]). However, the mechanistic model needs to i) include relevant biological processes involved in the response ii) to be fed enough data (that is with relevant markers measured repeatedly). In some circumstances such as in the ALBI trial this could be achieved, but more developments are probably needed to cope with the numerous types of drugs available today. The implementation of processes such as the occurrence of genotypic mutation or the effect of known host genotype on the treatment efficacy could be achieved without too much complexity. In such cases, however, the restriction might come from the absence of measured information. Also, in line with the parsimony principle that maximizes the external validity of the predictions, simple models should be prioritized. Then, if a good model proves relevant for current treatments, the next step would be to evaluate the potential of such approaches for treatment monitoring by well-designed clinical trials. 


\section{Acknowledgements}

We thank the Vaccine Research Institute for providing grant support and Carol Featherstone for the editing of the English. 


\section{References}

[1] S. M. Hammer, M. S. Saag, M. Schechter, J. S. G. Montaner, R. T. Schooley, D. M. Jacobsen, M. A. Thompson, C. C. J. Carpenter, M. A. Fischl, B. G. Gazzard, et others, « Treatment for adult HIV infection », JAMA: the journal of the American Medical Association, vol. 296, n ${ }^{\circ}$ 7, p. 827-843, 2006.

[2] P. W. Lavori et R. Dawson, « Adaptive treatment strategies in chronic disease », Annual review of medicine, vol. 59, p. 443- 453, 2008.

[3] D. Back, G. Gatti, C. Fletcher, R. Garaffo, R. Haubrich, R. Hoetelmans, M. Kurowski, A. Luber, C. Merry, et C. F. Perno, « Therapeutic drug monitoring in HIV infection: current status and future directions », Aids, vol. 16, p. S5-S37, 2002.

[4] J. G. Gerber et E. P. Acosta, « Therapeutic drug monitoring in the treatment of HIVinfection », Journal of Clinical Virology, vol. 27, $\mathrm{n}^{\mathrm{o}}$ 2, p. 117-128, 2003.

[5] D. J. Lunn, C. Wei, et R. Hovorka, « Fitting dynamic models with forcing functions: Application to continuous glucose monitoring in insulin therapy », Statistics in medicine, vol. 30, $\mathrm{n}^{\mathrm{o}} 18$, p. 2234-2250, 2011.

[6] S. Murphy, « Optimal dynamic treatment regimes », Journal of the Royal Statistical Society: Series B (Statistical Methodology), vol. 65, n² 2, p. 331-355, 2003.

[7] S. A. Murphy et J. R. McKay, « Adaptive treatment strategies: An emerging approach for improving treatment effectiveness », Clinical Science, vol. 12, nº 3, p. 7-13, 2004.

[8] D. E. Rivera, M. D. Pew, et L. M. Collins, « Using engineering control principles to inform the design of adaptive interventions: A conceptual introduction », Drug and alcohol dependence, vol. 88, p. S31-S40, 2007.

[9] R. F. Stengel et R. Ghigliazza, «Stochastic optimal therapy for enhanced immune response », Mathematical biosciences, vol. 191, $\mathrm{n}^{\circ}$ 2, p. 123-142, 2004.

[10] A. Yates, J. Stark, N. Klein, R. Antia, et R. Callard, « Understanding the slow depletion of memory CD4+ T cells in HIV infection », PLoS medicine, vol. 4, $\mathrm{n}^{\mathrm{0}} 5$, $\mathrm{p}$. e177, 2007.

[11] W. J. Boscardin, J. M. G. Taylor, et N. Law, « Longitudinal models for AIDS marker data », Statistical Methods in Medical Research, vol. 7, nº 1, p. 13-27, 1998.

[12] R. Thiébaut, H. Jacqmin-Gadda, C. Leport, C. Katlama, D. Costagliola, V. L. Moing, P. Morlat, G. Chêne, et A. S. Group, « Bivariate longitudinal model for the analysis of the evolution of HIV RNA and CD4 cell count in HIV infection taking into account left censoring of HIV RNA measures », Journal of Biopharmaceutical Statistics, vol. 13, $\mathrm{n}^{\mathrm{o}} 2$, p. 271-282, 2003.

[13] R. Thiébaut, H. Jacqmin-Gadda, A. Babiker, et D. Commenges, « Joint modelling of bivariate longitudinal data with informative dropout and left-censoring, with application to the evolution of CD4+ cell count and HIV RNA viral load in response to treatment of HIV infection », Statistics in medicine, vol. 24, $\mathrm{n}^{\mathrm{o}}$ 1, p. 65-82, 2005.

[14] E. R. Brown, J. G. Ibrahim, et V. DeGruttola, «A Flexible B-Spline Model for Multiple Longitudinal Biomarkers and Survival », Biometrics, vol. 61, n 1, p. 64-73, 2005.

[15] A. S. Perelson, A. U. Neumann, M. Markowitz, J. M. Leonard, et D. D. Ho, « HIV-1 dynamics in vivo: virion clearance rate, infected cell life-span, and viral generation time », Science, vol. 271, n ${ }^{\circ}$ 5255, p. 1582-1586, 1996.

[16] X. Wei, S. K. Ghosh, M. E. Taylor, V. A. Johnson, E. A. Emini, P. Deutsch, J. D. Lifson, S. Bonhoeffer, M. A. Nowak, et B. H. Hahn, « Viral dynamics in human immunodeficiency virus type 1 infection. », Nature, vol. 373, nº 6510, p. 117, 1995. 
[17] A. R. Sedaghat, C. O. Wilke, et others, « Kinetics of the viral cycle influence pharmacodynamics of antiretroviral therapy », Biology direct, vol. 6, $\mathrm{n}^{\circ}$ 1, p. 1-10, 2011.

[18] D. S. Callaway et A. S. Perelson, " HIV-1 infection and low steady state viral loads », Bulletin of mathematical biology, vol. 64, $\mathrm{n}^{\circ}$ 1, p. 29-64, 2002.

[19] A. S. Perelson et R. M. Ribeiro, « Estimating drug efficacy and viral dynamic parameters: HIV and HCV », Statistics in medicine, vol. 27, n 23, p. 4647-4657, 2008.

[20] S. Wu, Tang, Miao, et $\mathrm{Wu}$, « Modeling antiretroviral drug response for HIV-1 infected patients using differential equation models », Mathematical modeling of systems pharmacogenomics towards personalized drug delivery, vol. 65, 2013.

[21] D. D. Ho, A. U. Neumann, A. S. Perelson, W. Chen, J. M. Leonard, M. Markowitz, et others, "Rapid turnover of plasma virions and CD4 lymphocytes in HIV-1 infection », Nature, vol. 373, $\mathrm{n}^{\mathrm{0}}$ 6510, p. 123-126, 1995.

[22] S. Bonhoeffer, R. M. May, G. M. Shaw, et M. A. Nowak, "Virus dynamics and drug therapy », Proceedings of the National Academy of Sciences, vol. 94, n 13, p. 69716976, 1997.

[23] A. L. Lloyd, « The dependence of viral parameter estimates on the assumed viral life cycle: limitations of studies of viral load data ", Proceedings of the Royal Society of London. Series B: Biological Sciences, vol. 268, n 1469, p. 847-854, 2001.

[24] I. M. Rouzine, R. A. Sergeev, et A. I. Glushtsov, « Two types of cytotoxic lymphocyte regulation explain kinetics of immune response to human immunodeficiency virus ", Proceedings of the National Academy of Sciences of the United States of America, vol. 103, n 3, p. 666-671, 2006.

[25] S. Bonhoeffer et M. A. Nowak, «Pre-existence and emergence of drug resistance in HIV-1 infection », Proceedings of the Royal Society of London. Series B: Biological Sciences, vol. 264, n 1382, p. 631-637, 1997.

[26] J. M. Coffin et others, « HIV population dynamics in vivo: implications for genetic variation, pathogenesis, and therapy », SCIENCE-NEW YORK THEN WASHINGTON,p. 483-483, 1995.

[27] E. Vergu, A. Mallet, et J. L. Golmard, « A modeling approach to the impact of HIV mutations on the immune system », Computers in Biology and Medicine, vol. 35, $\mathrm{n}^{\mathrm{o}} 1$, p. 1-24, 2005.

[28] B. M. Adams, H. T. Banks, M. Davidian, H. D. Kwon, H. T. Tran, S. N. Wynne, et E. S. Rosenberg, « HIV dynamics: modeling, data analysis, and optimal treatment protocols », Journal of Computational and Applied Mathematics, vol. 184, n ${ }^{\circ} 1, \mathrm{p} .10$ 49, 2005.

[29] A. R. Sedaghat, J. B. Dinoso, L. Shen, C. O. Wilke, et R. F. Siliciano, « Decay dynamics of HIV-1 depend on the inhibited stages of the viral life cycle ", Proceedings of the National Academy of Sciences, vol. 105, $\mathrm{n}^{\mathrm{o}}$ 12, p. 4832-4837, 2008.

[30] R. J. Smith et L. M. Wahl, « Distinct effects of protease and reverse transcriptase inhibition in an immunological model of HIV-1 infection with impulsive drug effects », Bulletin of Mathematical Biology, vol. 66, $\mathrm{n}^{\circ}$ 5, p. 1259-1283, 2004.

[31] J. Guedj, R. Thiébaut, et D. Commenges, " Practical identifiability of HIV dynamics models », Bulletin of Mathematical Biology, vol. 69, $\mathrm{n}^{\circ}$ 8, p. 2493-2513, 2007.

[32] X. Xia et C. H. Moog, « Identifiability of nonlinear systems with application to HIV/AIDS models », Automatic Control, IEEE Transactions on, vol. 48, n 2, p. 330 336, 2003. 
[33] D. M. Bortz et P. W. Nelson, « Model selection and mixed-effects modeling of HIV infection dynamics », Bulletin of mathematical biology, vol. 68, ${ }^{\circ}$ 8, p. 2005-2025, 2006.

[34] D. P. Wilson et D. L. S. McElwain, « A mathematical model of continuous HIV mutations eluding immune defence ", Journal of Theoretical Medicine, vol. 4, $n^{\circ}$ 4, p. 241-249, 2002.

[35] L. M. Wein, R. M. D’Amato, et A. S. Perelson, « Mathematical analysis of antiretroviral therapy aimed at HIV-1 eradication or maintenance of low viral loads ", Journal of theoretical biology, vol. 192, $\mathrm{n}^{\mathrm{0}}$ 1, p. 81-98, 1998.

[36] H. Wu, "Statistical methods for HIV dynamic studies in AIDS clinical trials », Statistical Methods in Medical Research, vol. 14, n 2, p. 171-192, 2005.

[37] H. Putter, S. Heisterkamp, J. Lange, et F. De Wolf, « A Bayesian approach to parameter estimation in HIV dynamical models ", Statistics in Medicine, vol. 21, ${ }^{0}$ 15, p. 2199-2214, 2002.

[38] Y. Huang, D. Liu, et H. Wu, « Hierarchical Bayesian methods for estimation of parameters in a longitudinal HIV dynamic system », Biometrics, vol. 62, n 2, p. 413423, 2006.

[39] J. Guedj, R. Thiébaut, et D. Commenges, « Maximum likelihood estimation in dynamical models of HIV », Biometrics, vol. 63, n 4, p. 1198-1206, 2007.

[40] Y. Huang, H. Wu, et E. P. Acosta, « Hierarchical Bayesian inference for HIV dynamic differential equation models incorporating multiple treatment factors $»$, Biometrical Journal, vol. 52, n ${ }^{\circ}$ 4, p. 470-486, 2010.

[41] E. Kuhn et M. Lavielle, « Maximum likelihood estimation in nonlinear mixed effects models », Computational Statistics \& Data Analysis, vol. 49, nº 4, p. 1020-1038, 2005.

[42] J. M. Molina, G. Chêne, F. Ferchal, V. Journot, I. Pellegrin, M. N. Sombardier, C. Rancinan, L. Cotte, I. Madelaine, T. Debord, et others, « The ALBI trial: a randomized controlled trial comparing stavudine plus didanosine with zidovudine plus lamivudine and a regimen alternating both combinations in previously untreated patients infected with human immunodeficiency virus », Journal of Infectious Diseases, vol. 180, n 2, p. 351-358, 1999.

[43] J. Drylewicz, D. Commenges, et R. Thiébaut, « Score tests for exploring complex models: application to HIV dynamics models », Biometrical Journal, vol. 52, n 1, p. 10-21, 2010.

[44] M. Von Kleist, S. Menz, et W. Huisinga, « Drug-class specific impact of antivirals on the reproductive capacity of HIV », PLoS computational biology, vol. 6, n ${ }^{\circ} 3$, p. e1000720, 2010.

[45] M. Prague, D. Commenges, J. Guedj, J. Drylewicz, et R. Thiébaut, « NIMROD: A Program for Inference via Normal Approximation of the Posterior in Models with Random effects based on Ordinary Differential Equations. », juill-2012.

[46] E. L. Plan, A. Maloney, F. Mentré, M. O. Karlsson, et J. Bertrand, « Performance Comparison of Various Maximum Likelihood Nonlinear Mixed-Effects Estimation Methods for Dose-Response Models », The AAPS journal, p. 1-13, 2012.

[47] M. Prague, D. Commenges, J. Drylewicz, et R. Thiébaut, « Treatment Monitoring of HIV-Infected Patients based on Mechanistic Models », Biometrics, 2012.

[48] V. Picard, E. Angelini, A. Maillard, E. Race, F. Clavel, G. Chêne, F. Ferchal, et J. M. Molina, « Comparison of genotypic and phenotypic resistance patterns of human immunodeficiency virus type 1 isolates from patients treated with stavudine and didanosine or zidovudine and lamivudine », Journal of Infectious Diseases, vol. 184, $\mathrm{n}^{\mathrm{o}}$ 6, p. 781-784, 2001. 
[49] G. Antonelli et O. Turriziani, « Antiviral therapy: old and current issues », International journal of antimicrobial agents, 2012.

[50] A. S. Perelson et P. W. Nelson, « Mathematical analysis of HIV-I: dynamics in vivo », SIAM review, vol. 41, n ${ }^{\circ}$ 1, p. 3-44, 1999.

[51] H. Wu et A. A. Ding, «Population HIV-1 Dynamics In Vivo: Applicable Models and Inferential Tools for Virological Data from AIDS Clinical Trials », Biometrics, vol. $55, \mathrm{n}^{\mathrm{o}} 2$, p. $410-418,1999$.

[52] M. Markowitz, M. Louie, A. Hurley, E. Sun, M. Di Mascio, A. S. Perelson, et D. D. Ho, «A novel antiviral intervention results in more accurate assessment of human immunodeficiency virus type 1 replication dynamics and T-cell decay in vivo ", Journal of virology, vol. 77, $\mathrm{n}^{\circ}$ 8, p. 5037, 2003.

[53] E. P. Acosta, K. L. Limoli, L. Trinh, N. T. Parkin, J. R. King, J. M. Weidler, I. Ofotokun, et C. J. Petropoulos, « Novel method to assess antiretroviral target trough concentrations using in vitro susceptibility data », Antimicrobial Agents and Chemotherapy, 2012.

[54] M. Boffito, D. J. Back, T. F. Blaschke, M. Rowland, R. J. Bertz, J. G. Gerber, et V. Miller, "Protein binding in antiretroviral therapies », AIDS research and human retroviruses, vol. 19, $\mathrm{n}^{\circ}$ 9, p. 825-835, 2003.

[55] C. Bazzoli, V. Jullien, C. Le Tiec, E. Rey, F. Mentré, et A. M. Taburet, « Intracellular pharmacokinetics of antiretroviral drugs in HIV-infected patients, and their correlation with drug action », Clinical pharmacokinetics, vol. 49, $\mathrm{n}^{\mathrm{o}}$ 1, p. 17-45, 2010.

[56] J. L. Casado, A. Moreno, R. Sabido, P. Martí-Belda, A. Antela, F. Dronda, M. J. Perez-Elías, et S. Moreno, « Individualizing salvage regimens: the inhibitory quotient (Ctrough/IC50) as predictor of virological response ", Aids, vol. 17, n 2, p. 262-264, 2003.

[57] H. Zhang, Y. Zhou, C. Alcock, T. Kiefer, D. Monie, J. Siliciano, Q. Li, P. Pham, J. Cofrancesco, D. Persaud, et others, « Novel single-cell-level phenotypic assay for residual drug susceptibility and reduced replication capacity of drug-resistant human immunodeficiency virus type $1 »$, Journal of virology, vol. 78, nº 4, p. 1718-1729, 2004.

[58] L. Shen, S. Peterson, A. R. Sedaghat, M. A. McMahon, M. Callender, H. Zhang, Y. Zhou, E. Pitt, K. S. Anderson, E. P. Acosta, et others, « Dose-response curve slope sets class-specific limits on inhibitory potential of anti-HIV drugs ", Nature medicine, vol. 14, no 7, p. 762-766, 2008.

[59] T. J. Henrich, H. J. Ribaudo, et D. R. Kuritzkes, « Instantaneous inhibitory potential is similar to inhibitory quotient at predicting HIV-1 response to antiretroviral therapy », Clin. Infect. Dis., vol. 51, n 1, p. 93- 98, juill. 2010.

[60] L. Shen, S. A. Rabi, et R. F. Siliciano, « A novel method for determining the inhibitory potential of anti-HIV drugs », Trends in pharmacological sciences, vol. 30, $\mathrm{n}^{\mathrm{o}} 12$, p. 610-616, 2009.

[61] A. Jackson, S. Taylor, M. Boffito, et others, « Pharmacokinetics and pharmacodynamics of drug interactions involving HIV-1 protease inhibitors », AIDS Rev, vol. 6, p. 208-217, 2004.

[62] J. B. Fitzgerald, B. Schoeberl, U. B. Nielsen, et P. K. Sorger, « Systems biology and combination therapy in the quest for clinical efficacy », Nature chemical biology, vol. 2, no 9, p. 458-466, 2006.

[63] B. L. Jilek, M. Zarr, M. E. Sampah, S. A. Rabi, C. K. Bullen, J. Lai, L. Shen, et R. F. Siliciano, "A quantitative basis for antiretroviral therapy for HIV-1 infection », Nature medicine, vol. 18, $\mathrm{n}^{\mathrm{O}} 3$, p. 446-451, 2012. 
[64] N. Buss et N. Cammack, " Measuring the effectiveness of antiretroviral agents », Antiviral therapy, vol. 6, $\mathrm{n}^{\circ}$ 1, p. 1-8, 2001.

[65] M. Barry, S. Gibbons, D. Back, F. Mulcahy, et others, « Protease inhibitors in patients with HIV disease. Clinically important pharmacokinetic considerations. », Clinical pharmacokinetics, vol. 32, n 3, p. 194, 1997.

[66] H. Wu, Y. Huang, E. P. Acosta, J. G. Park, S. Yu, S. L. Rosenkranz, D. R. Kuritzkes, J. J. Eron, A. S. Perelson, et J. G. Gerber, « Pharmacodynamics of antiretroviral agents in HIV-1 infected patients: using viral dynamic models that incorporate drug susceptibility and adherence », Journal of pharmacokinetics and pharmacodynamics, vol. 33, nº 4, p. 399-419, 2006.

[67] J. Fang et P. R. Jadhav, « From in vitro EC 50 to in vivo dose-response for antiretrovirals using an HIV disease model. Part I: A framework », Journal of pharmacokinetics and pharmacodynamics, p. 1-12, 2012.

[68] A. J. Claxton, J. Cramer, et C. Pierce, « A systematic review of the associations between dose regimens and medication compliance », Clinical therapeutics, vol. 23, $\mathrm{n}^{\mathrm{o}} 8$, p. 1296-1310, 2001.

[69] C. L. Besch, « Compliance in clinical trials », AIDS, vol. 9, nº 1, p. 1- 10, janv. 1995.

[70] E. M. Gardner, W. J. Burman, J. F. Steiner, P. L. Anderson, et D. R. Bangsberg, « Antiretroviral medication adherence and the development of class-specific antiretroviral resistance », AIDS, vol. 23, n 9, p. 1035- 1046, juin 2009.

[71] D. R. Bangsberg, A. R. Moss, et S. G. Deeks, « Paradoxes of adherence and drug resistance to HIV antiretroviral therapy », J. Antimicrob. Chemother., vol. 53, $\mathrm{n}^{\circ}$ 5, p. 696- 699, janv. 2004.

[72] J. R. Ickovics et A. W. Meisler, « Adherence in AIDS clinical trials: A framework for clinical research and clinical care », Journal of Clinical Epidemiology, vol. 50, $\mathrm{n}^{\circ}$ 4, p. 385- 391, avr. 1997.

[73] H. Wu, Y. Huang, E. P. Acosta, S. L. Rosenkranz, D. R. Kuritzkes, J. J. Eron, A. S. Perelson, et J. G. Gerber, « Modeling long-term HIV dynamics and antiretroviral response: effects of drug potency, pharmacokinetics, adherence, and drug resistance ", JAIDS Journal of Acquired Immune Deficiency Syndromes, vol. 39, n 3, p. 272-283, 2005.

[74] L. M. Wahl et M. A. Nowak, « Adherence and drug resistance: predictions for therapy outcome. », Proc Biol Sci, vol. 267, n 1445, p. 835- 843, avr. 2000.

[75] R. J. Smith, « Adherence to antiretroviral HIV drugs: how many doses can you miss before resistance emerges? », Proc. R. Soc. B, vol. 273, n 1586, p. 617- 624, juill. 2006.

[76] D. I. S. Rosenbloom, A. L. Hill, S. A. Rabi, R. F. Siliciano, et M. A. Nowak, " Antiretroviral dynamics determines HIV evolution and predicts therapy outcome », Nature Medicine, vol. 18, no 9, p. 1378- 1385, 2012.

[77] L. Rong, Z. Feng, et A. S. Perelson, «Emergence of HIV-1 drug resistance during antiretroviral treatment », Bulletin of mathematical biology, vol. 69, $\mathrm{n}^{\circ}$ 6, p. 20272060, 2007.

[78] S. G. Deeks et D. I. Abrams, « Genotypic-resistance assays and antiretroviral therapy », The Lancet, vol. 349, nº 9064, p. 1489- 1490, mai 1997.

[79] M. E. Quiñones-Mateu et E. J. Arts, « HIV-1 fitness: implications for drug resistance, disease progression, and global epidemic evolution », HIV sequence compendium, vol. 2001, p. 134-170, 2001.

[80] K. Hertogs, M.-P. de Béthune, V. Miller, T. Ivens, P. Schel, A. V. Cauwenberge, C. V. den Eynde, V. van Gerwen, H. Azijn, M. van Houtte, F. Peeters, S. Staszewski, M. Conant, S. Bloor, S. Kemp, B. Larder, et R. Pauwels, « A Rapid Method for 
Simultaneous Detection of Phenotypic Resistance to Inhibitors of Protease and Reverse Transcriptase in Recombinant Human Immunodeficiency Virus Type 1 Isolates from Patients Treated with Antiretroviral Drugs », Antimicrobial Agents and Chemotherapy, vol. 42, n ${ }^{\circ}$ 2, p. 269, févr. 1998.

[81] C. J. Petropoulos, N. T. Parkin, K. L. Limoli, Y. S. Lie, T. Wrin, W. Huang, H. Tian, D. Smith, G. A. Winslow, D. J. Capon, et J. M. Whitcomb, « A Novel Phenotypic Drug Susceptibility Assay for Human Immunodeficiency Virus Type $1 »$, Antimicrob Agents Chemother, vol. 44, $\mathrm{n}^{\mathrm{o}}$ 4, p. 920- 928, avr. 2000.

[82] N. Shulman, A. Zolopa, D. Havlir, A. Hsu, C. Renz, S. Boller, P. Jiang, R. Rode, J. Gallant, E. Race, et others, «Virtual inhibitory quotient predicts response to ritonavir boosting of indinavir-based therapy in human immunodeficiency virus-infected patients with ongoing viremia », Antimicrobial agents and chemotherapy, vol. 46, $\mathrm{n}^{0}$ 12, p. 3907-3916, 2002.

[83] M. E. S. Sampah, L. Shen, B. L. Jilek, et R. F. Siliciano, « Dose-response curve slope is a missing dimension in the analysis of HIV-1 drug resistance », Proceedings of the National Academy of Sciences, vol. 108, nº 18, p. 7613-7618, 2011.

[84] L. Wittkop, D. Commenges, I. Pellegrin, D. Breilh, D. Neau, D. Lacoste, J.-L. Pellegrin, G. Chêne, F. Dabis, et R. Thiébaut, « Alternative methods to analyse the impact of HIV mutations on virological response to antiviral therapy », BMC Medical Research Methodology, vol. 8, $\mathrm{n}^{\mathrm{0}}$ 1, p. 68, oct. 2008.

[85] M. A. Nowak, R. M. May, et R. M. Anderson, « The evolutionary dynamics of HIV-1 quasispecies and the development of immunodeficiency disease $»$, Aids, vol. 4, $\mathrm{n}^{\mathrm{0}} 11$, p. 1095-1103, 1990.

[86] L. M. Wein, S. A. Zenios, et M. A. Nowak, « Dynamic multidrug therapies for HIV: a control theoretic approach », Journal of Theoretical Biology, vol. 185, $\mathrm{n}^{\mathrm{o}}$ 1, p. 15-29, 1997.

[87] R. M. Ribeiro et S. Bonhoeffer, «Production of resistant HIV mutants during antiretroviral therapy ", Proceedings of the National Academy of Sciences, vol. 97, $\mathrm{n}^{\circ}$ 14, p. 7681-7686, 2000.

[88] L. Rong, M. A. Gilchrist, Z. Feng, et A. S. Perelson, « Modeling within-host HIV-1 dynamics and the evolution of drug resistance: trade-offs between viral enzyme function and drug susceptibility », J. Theor. Biol., vol. 247, n 4, p. 804- 818, août 2007.

[89] J. Durant, P. Clevenbergh, P. Halfon, P. Delgiudice, S. Porsin, P. Simonet, N. Montagne, C. Boucher, J. Schapiro, et P. Dellamonica, « Drug-resistance genotyping in HIV-1 therapy: the VIRAD APT randomi sed controlled trial », The Lancet, vol. $353, n^{\circ} 9171$, p. 2195 - 2199, juin 1999.

[90] E. Domingo et J. J. Holland, « RNA virus mutations and fitness for survival », Annual Reviews in Microbiology, vol. 51, $\mathrm{n}^{\circ}$ 1, p. 151-178, 1997.

[91] D. Turner, B. Brenner, et M. A. Wainberg, « Multiple Effects of the M184V Resistance Mutation in the Reverse Transcriptase of Human Immunodeficiency Virus Type 1 », Clin Diagn Lab Immunol, vol. 10, nº 6, p. 979- 981, nov. 2003.

[92] H. Wu, Y. Huang, C. Dykes, D. Liu, J. Ma, A. S. Perelson, et L. M. Demeter, « Modeling and estimation of replication fitness of human immunodeficiency virus type 1 in vitro experiments by using a growth competition assay », Journal of virology, vol. 80, $\mathrm{n}^{\mathrm{o}}$ 5, p. 2380-2389, 2006.

[93] H. Miao, C. Dykes, L. M. Demeter, et H. Wu, « Differential equation modeling of HIV viral fitness experiments: model identification, model selection, and multimodel inference », Biometrics, vol. 65, nº 1, p. 292-300, 2009. 
[94] S. Mallal, E. Phillips, G. Carosi, J.-M. Molina, C. Workman, J. Tomažič, E. JägelGuedes, S. Rugina, O. Kozyrev, J. F. Cid, P. Hay, D. Nolan, S. Hughes, A. Hughes, S. Ryan, N. Fitch, D. Thorborn, et A. Benbow, « HLA-B*5701 Screening for Hypersensitivity to Abacavir », New England Journal of Medicine, vol. 358, n ${ }^{\circ}$ 6, p. 568- 579, 2008.

[95] R. M. Savic, A. Barrail-Tran, X. Duval, G. Nembot, X. Panhard, D. Descamps, C. Verstuyft, B. Vrijens, A. M. Taburet, et C. Goujard, « Effect of Adherence as Measured by MEMS, Ritonavir Boosting, and CYP3A5 Genotype on Atazanavir Pharmacokinetics in Treatment-Naive HIV-Infected Patients », Clinical Pharmacology \& Therapeutics, vol. 92, $\mathrm{n}^{\circ}$ 5, p. 575-583, 2012.

[96] A. Telenti et U. M. Zanger, «Pharmacogenetics of Anti-HIV Drugs », Annual Review of Pharmacology and Toxicology, vol. 48, $\mathrm{n}^{\mathrm{o}}$ 1, p. 227- 256, 2008.

[97] V. Michaud, T. Bar-Magen, J. Turgeon, D. Flockhart, Z. Desta, et M. A. Wainberg, « The dual role of pharmacogenetics in HIV treatment: mutations and polymorphisms regulating antiretroviral drug resistance and disposition », Pharmacol. Rev., vol. 64, $\mathrm{n}^{\mathrm{o}}$ 3, p. $803-833$, juill. 2012.

[98] J. Bertrand, J. M. Treluyer, X. Panhard, A. Tran, S. Auleley, E. Rey, D. SalmonCéron, X. Duval, et F. Mentré, «Influence of pharmacogenetics on indinavir disposition and short-term response in HIV patients initiating HAART », European journal of clinical pharmacology, vol. 65, n 7, p. 667-678, 2009.

[99] J. Bertrand, M. Chou, D. M. Richardson, C. Verstuyft, P. D. Leger, F. Mentré, A. M. Taburet, et D. W. Haas, « Multiple genetic variants predict steady-state nevirapine clearance in HIV-infected Cambodians », Pharmacogenetics and Genomics, vol. 22, $\mathrm{n}^{\mathrm{o}} 12$, p. 868-876, 2012.

[100] M. Hecker, S. Lambeck, S. Toepfer, E. van Someren, et R. Guthke, « Gene regulatory network inference: Data integration in dynamic models-A », Biosystems, vol. 96, p. 86-103, 2009.

[101] T. Lu, H. Liang, H. Li, et H. Wu, « High-Dimensional ODEs Coupled With MixedEffects Modeling Techniques for Dynamic Gene Regulatory Network Identification », Journal of the American Statistical Association, vol. 106, nº 496, p. 1242-1258, 2011.

[102] M. Egger, M. May, G. Chêne, A. N. Phillips, B. Ledergerber, F. Dabis, D. Costagliola, A. D. A. Monforte, F. de Wolf, P. Reiss, et others, " Prognosis of HIV-1infected patients starting highly active antiretroviral therapy: a collaborative analysis of prospective studies* », The Lancet, vol. 360, n ${ }^{\circ}$ 9327, p. 119-129, 2002.

[103] R. Thiébaut, G. Chêne, H. Jacqmin-Gadda, P. Morlat, P. Mercié, M. Dupon, D. Neau, H. Ramaroson, F. Dabis, et R. Salamon, « Time-updated CD4+ T lymphocyte count and HIV RNA as major markers of disease progression in naive HIV-1-infected patients treated with a highly active antiretroviral therapy: the Aquitaine cohort, 1996$2001 »$, JAIDS Journal of Acquired Immune Deficiency Syndromes, vol. 33, nº 3, p. 380-386, 2003.

[104] M. D. Hughes, M. J. Daniels, M. A. Fischl, S. Kim, et R. T. Schooley, « CD4 cell count as a surrogate endpoint in HIV clinical trials: a meta-analysis of studies of the AIDS Clinical Trials Group », Aids, vol. 12, n 14, p. 1823-1832, 1998.

[105] HIV SURROGATE MARKER COLLABORATIVE GROUP, « Human Immunodeficiency Virus Type 1 RNA Level and CD4 Count as Prognostic Markers and Surrogate End Points: A Meta-Analysis », AIDS Research and Human Retroviruses, vol. 16, $\mathrm{n}^{\mathrm{o}}$ 12, p. 1123-1133, 2000.

[106] C. Lewden, T. May, E. Rosenthal, C. Burty, F. Bonnet, D. Costagliola, E. Jougla, C. Semaille, P. Morlat, et D. Salmon, «Changes in causes of death among adults infected by HIV between 2000 and 2005: The“" Mortalite 2000 and 2005" surveys (ANRS 
EN19 and Mortavic) », JAIDS Journal of Acquired Immune Deficiency Syndromes, vol. 48, n⿳⺈ 5, p. 590-598, 2008.

[107] D. Abrams, Y. Lévy, M. H. Losso, A. Babiker, G. Collins, D. Cooper, J. Darbyshire, S. Emery, L. Fox, et F. Gordin, « Interleukin-2 therapy in patients with HIV infection. », The New England journal of medicine, vol. 361, n ${ }^{\circ} 16$, p. 1548-59, 2009.

[108] V. De Gruttola et X. M. Tu, « Modelling progression of CD4-lymphocyte count and its relationship to survival time », Biometrics, p. 1003-1014, 1994.

[109] A. A. Tsiatis et M. Davidian, « Joint modeling of longitudinal and time-to-event data: an overview », Statistica Sinica, vol. 14, n 3, p. 809-834, 2004.

[110] X. Song, M. Davidian, et A. A. Tsiatis, « A Semiparametric Likelihood Approach to Joint Modeling of Longitudinal and Time-to-Event Data », Biometrics, vol. 58, $\mathrm{n}^{\circ}$ 4, p. 742-753, 2004.

[111] N. Pantazis, G. Touloumi, A. S. Walker, et A. G. Babiker, « Bivariate modelling of longitudinal measurements of two human immunodeficiency type 1 disease progression markers in the presence of informative drop-outs », Journal of the Royal Statistical Society: Series C (Applied Statistics), vol. 54, nº 2, p. 405-423, 2005.

[112] L. Wu, X. J. Hu, et H. Wu, « Joint inference for nonlinear mixed-effects models and time to event at the presence of missing data », Biostatistics, vol. 9, $\mathrm{n}^{\mathrm{o}} 2, \mathrm{p} .308-320$, 2008.

[113] J. Guedj, R. Thiébaut, et D. Commenges, « Joint modeling of the clinical progression and of the biomarkers' dynamics using a mechanistic model », Biometrics, vol. 67, $\mathrm{n}^{\circ}$ 1, p. 59-66, 2011.

[114] R. C. Kaplan, P. C. Tien, J. Lazar, R. Zangerle, M. Sarcletti, T. M. Pollack, D. M. Rind, C. Sabin, N. Friis-Møller, et J. D. Lundgren, « Antiretroviral drugs and the risk of myocardial infarction », New England Journal of Medicine, vol. 357, n 7, p. 715$717,2007$.

[115] J. H. Stein, « Cardiovascular risks of antiretroviral therapy », New England Journal of Medicine, vol. 356, $\mathrm{n}^{\mathrm{O}}$ 17, p. 1773-1775, 2007.

[116] S. A. Murphy, K. G. Lynch, D. Oslin, J. R. McKay, et T. TenHave, « Developing adaptive treatment strategies in substance abuse research », Drug and alcohol dependence, vol. 88, p. S24-S30, 2007.

[117] E. S. Rosenberg, M. Davidian, et H. T. Banks, « Using mathematical modeling and control to develop structured treatment interruption strategies for HIV infection », Drug and alcohol dependence, vol. 88, p. S41-S51, 2007.

[118] Y. Lévy, C. Durier, A. S. Lascaux, V. Meiffrédy, H. Gahéry-Ségard, C. Goujard, C. Rouzioux, M. Resch, J. G. Guillet, et M. Kazatchkine, « Sustained control of viremia following therapeutic immunization in chronically HIV-1-infected individuals », Aids, vol. 20, n⿳⺈ 3, p. 405-413, 2006.

[119] Y. Lévy, R. Thiébaut, M. L. Gougeon, J. M. Molina, L. Weiss, P. M. Girard, A. Venet, P. Morlat, B. Poirier, et A. S. Lascaux, « Effect of intermittent interleukin-2 therapy on CD4+ T-cell counts following antiretroviral cessation in patients with HIV », AIDS, vol. 26, n 6, p. 711, 2012.

[120] W. M. El-Sadr, J. D. Lundgren, J. D. Neaton, F. Gordin, D. Abrams, R. C. Arduino, A. Babiker, W. Burman, N. Clumeck, et C. J. Cohen, « CD4+ count-guided interruption of antiretroviral treatment », New Engl J Med, vol. 355, n ${ }^{\circ} 22$, p. 22832296, 2006.

[121] D. Kirschner, S. Lenhart, et S. Serbin, « Optimal control of the chemotherapy of HIV », Journal of Mathematical Biology, vol. 35, nº 7, p. 775-792, 1997.

[122] D. J. Austin, N. J. White, et R. M. Anderson, « The Dynamics of Drug Action on the Within-host Population Growth of Infectious Agents: Melding Pharmacokinetics with 
Pathogen Population Dynamics », Journal of Theoretical Biology, vol. 194, nº 3, p. 313-339, oct. 1998.

[123] M. J. Van Der Laan et M. L. Petersen, « Causal effect models for realistic individualized treatment and intention to treat rules », The International Journal of Biostatistics, vol. 3, $\mathrm{n}^{\mathrm{o}}$ 1, p. 1-53, 2007.

[124] X. Duval, F. Mentré, E. Rey, S. Auleley, G. Peytavin, M. Biour, A. Métro, C. Goujard, A.-M. Taburet, C. Lascoux, X. Panhard, J.-M. Tréluyer, et D. Salmon-Céron, «Benefit of therapeutic drug monitoring of protease inhibitors in HIV-infected patients depends on PI used in HAART regimen--ANRS 111 trial », Fundam Clin Pharmacol, vol. 23, nº 4, p. 491 - 500, août 2009.

[125] D. J. Back, S. H. Khoo, S. E. Gibbons, et C. Merry, « The role of therapeutic drug monitoring in treatment of HIV infection », BrJ Clin Pharmacol, vol. 51, $\mathrm{n}^{\circ}$ 4, p. 301-308, avr. 2001.

[126] S. H. Khoo, J. Lloyd, M. Dalton, A. Bonington, E. Hart, S. Gibbons, P. Flegg, J. Sweeney, E. G. L. Wilkins, et D. J. Back, «Pharmacologic optimization of protease inhibitors and nonnucleoside reverse transcriptase inhibitors (POPIN)--a randomized controlled trial of therapeutic drug monitoring and adherence support », J. Acquir. Immune Defic. Syndr., vol. 41, no 4, p. 461 - 467, avr. 2006.

[127] J. D. Baxter, D. L. Mayers, D. N. Wentworth, J. D. Neaton, M. L. Hoover, M. A. Winters, S. B. Mannheimer, M. A. Thompson, D. I. Abrams, et B. J. Brizz, « A randomized study of antiretroviral management based on plasma genotypic antiretroviral resistance testing in patients failing therapy », Aids, vol. 14, n ${ }^{\circ}$, p. F83F93, 2000.

[128] C. J. Cohen, S. Hunt, M. Sension, C. Farthing, M. Conant, S. Jacobson, J. Nadler, W. Verbiest, K. Hertogs, et M. Ames, «A randomized trial assessing the impact of phenotypic resistance testing on antiretroviral therapy », Aids, vol. 16, nº 4, p. 579$588,2002$.

[129] J. L. Meynard, M. Vray, L. Morand-Joubert, E. Race, D. Descamps, G. Peytavin, S. Matheron, C. Lamotte, S. Guiramand, et D. Costagliola, « Phenotypic or genotypic resistance testing for choosing antiretroviral therapy after treatment failure: a randomized trial », Aids, vol. 16, n ${ }^{\circ}$ 5, p. 727-736, 2002.

[130] S. A. Murphy, « An experimental design for the development of adaptive treatment strategies », Statistics in medicine, vol. 24, n 10, p. 1455-1481, 2005.

[131] B. M. Best, M. Goicoechea, M. D. Witt, L. Miller, E. S. Daar, C. Diamond, J. G. Tilles, C. A. Kemper, R. Larsen, D. T. Holland, S. Sun, S. Jain, G. Wagner, E. V. Capparelli, J. A. McCutchan, et R. H. Haubrich, « A Randomized Controlled Trial of Therapeutic Drug Monitoring in Treatment-Naive and -Experienced HIV-1-Infected Patients », JAIDS Journal of Acquired Immune Deficiency Syndromes, vol. 46, nº 4, p. 433- 442, déc. 2007.

[132] Y. Lévy, I. Sereti, G. Tambussi, J. P. Routy, J. D. Lelièvre, J. F. Delfraissy, J. M. Molina, M. Fischl, C. Goujard, B. Rodriguez, C. Rouzioux, V. Avettand-Fenoël, T. Croughs, S. Beq, M. Morre, J. F. Poulin, R. P. Sekaly, R. Thiebaut, et M. M. Lederman, « Effects of Recombinant Human Interleukin 7 on T-Cell Recovery and Thymic Output in HIV-Infected Patients Receiving Antiretroviral Therapy: Results of a Phase I/IIa Randomized, Placebo-Controlled, Multicenter Study », Clin Infect Dis, vol. 55, nº 2, p. $291-300$, juill. 2012.

[133] M. A. McMahon, L. Shen, et R. F. Siliciano, « New approaches for quantitating the inhibition of HIV-1 replication by antiviral drugs in vitro and in vivo », Curr. Opin. Infect. Dis., vol. 22, n ${ }^{\mathrm{O}}$ 6, p. 574- 582, déc. 2009. 


\section{Tables and figures}

Figure 1 - Graphical representation of the "Activated cells model"

Figure 2 - Viral load (log10 copies/ml) and CD4 count (cells/L) predictions for patients at median of the final HIV viral load distribution for patients in ALBI switch arm (\#642). Triangles are observations, Red Diamonds are observations outside the CI; Black lines are fits, blue line on the left of the horizontal line is prediction. Shaded zone represents the $\mathbf{9 5 \%}$ measurement error predictive interval. Horizontal dashed line represent left censoring threshold for viral load. Bottom part of graphs gives treatment posology.

Figure 3 - Viral load (log10 copies/ml) and CD4 count (cells/L) predictions for patients at quartiles (Q1 and median) of the final HIV viral load distribution for patients in ALBI experiencing dose changes. Triangles are observations, Red Diamonds are observations outside the CI; Black lines are fits, blue line on the left of the horizontal line is prediction. Shaded zone represents the $95 \%$ measurement error predictive interval. Horizontal dashed line represent left censoring threshold for viral load. Bottom part of graphs gives treatment posology.

Figure 4 - Viral load (log10 copies/ml) and CD4 count (cells/L) predictions for patient at third quartile (Q3) of the final HIV viral load distribution for patients in ALBI experiencing dose changes. Triangles are observations, Red Diamonds are observations outside the CI; Black lines are fits, blue line on the left of the horizontal line is prediction. Shaded zone represents the $\mathbf{9 5 \%}$ measurement error predictive interval. Horizontal dashed line represent left censoring threshold for viral load. Bottom part of graphs gives treatment posology. Two graphs at the lower part of the figure represent predictions for the same patient (Q3) demanding on the number of observations used to construct predictions. Left is on a long-term (1 observation used to predict a 6 points trajectory) and on a short term (3 observations used to predict a 3 points trajectory).

(a) Only the baseline observation is used to build long-term predictions.

(b) First three observations are used to build shorter-term predictions.

Figure 5 - Flow chart of a standard clinical trial testing TDM against SOC. 
Click here to download high resolution image

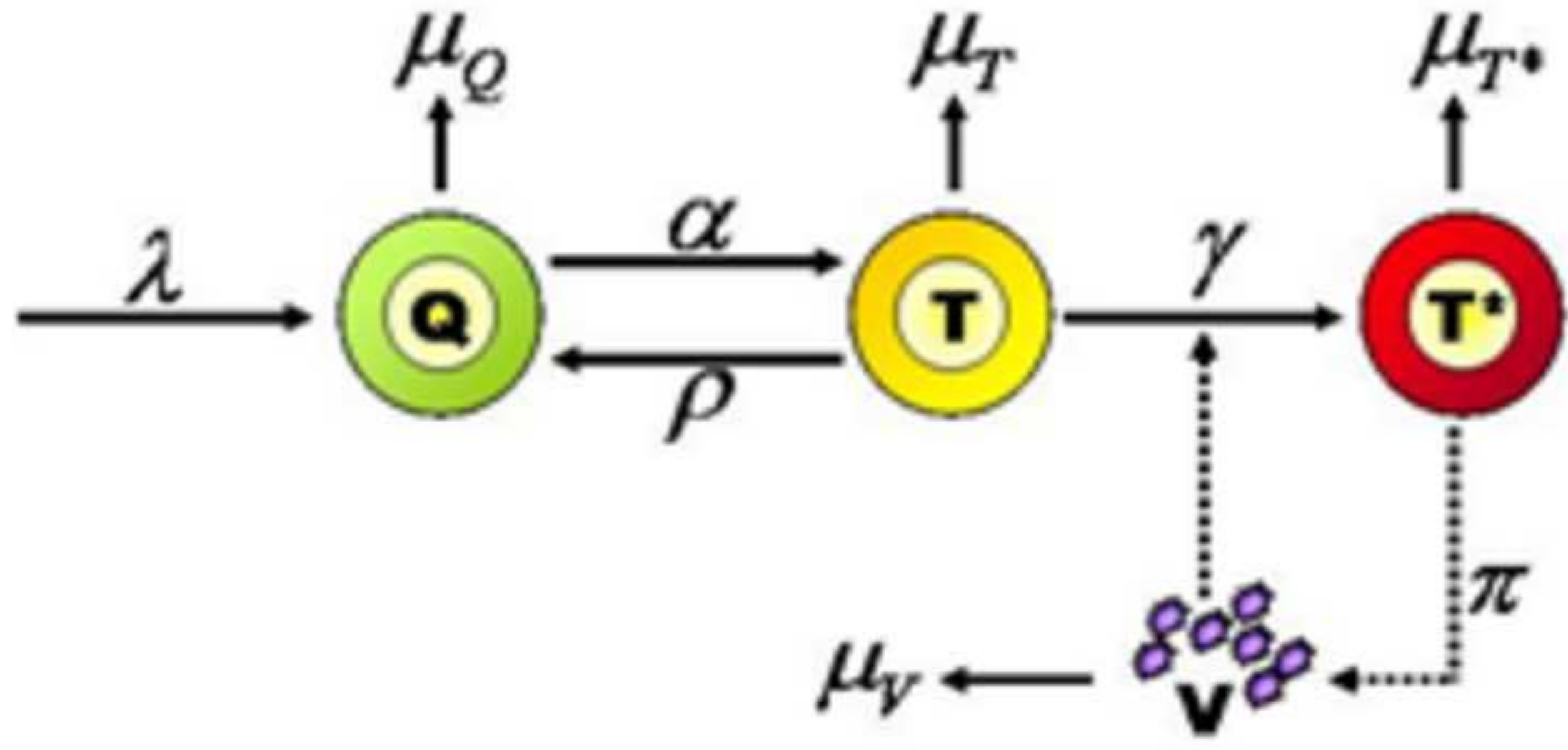



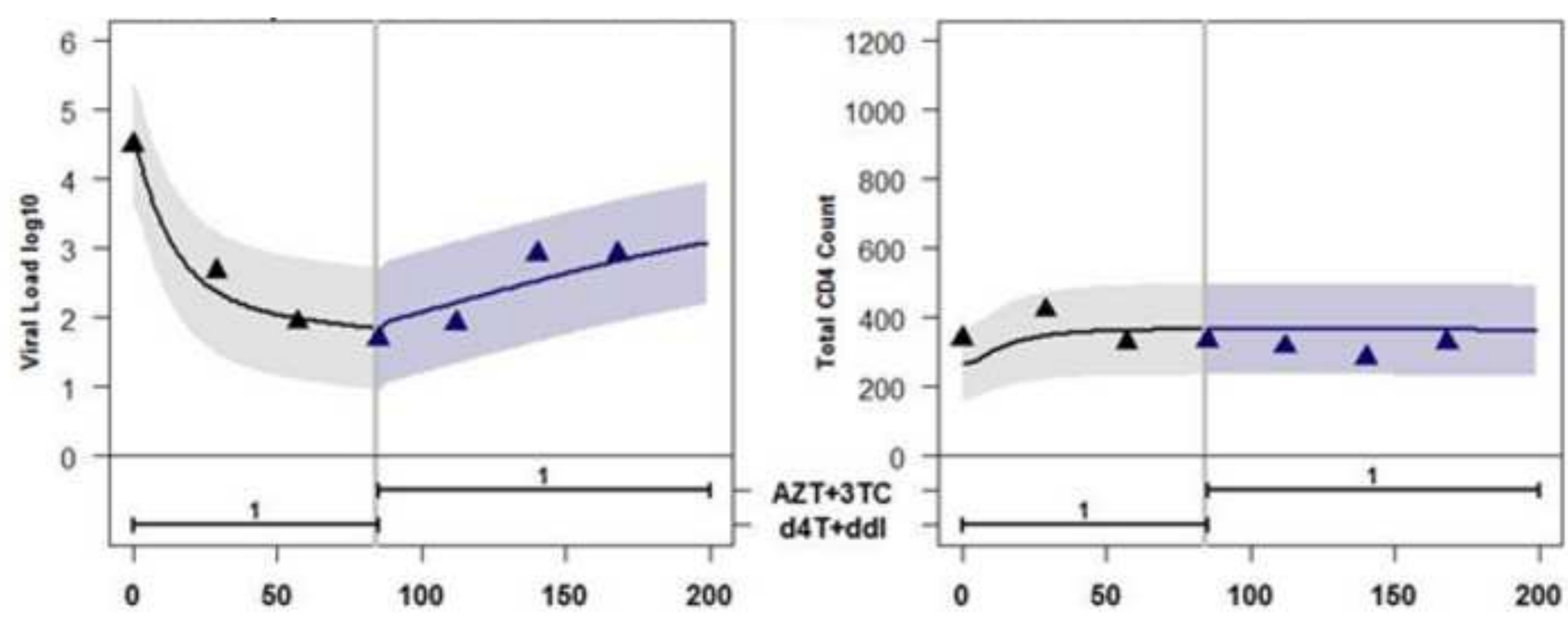

\section{0}


Click here to download high resolution image
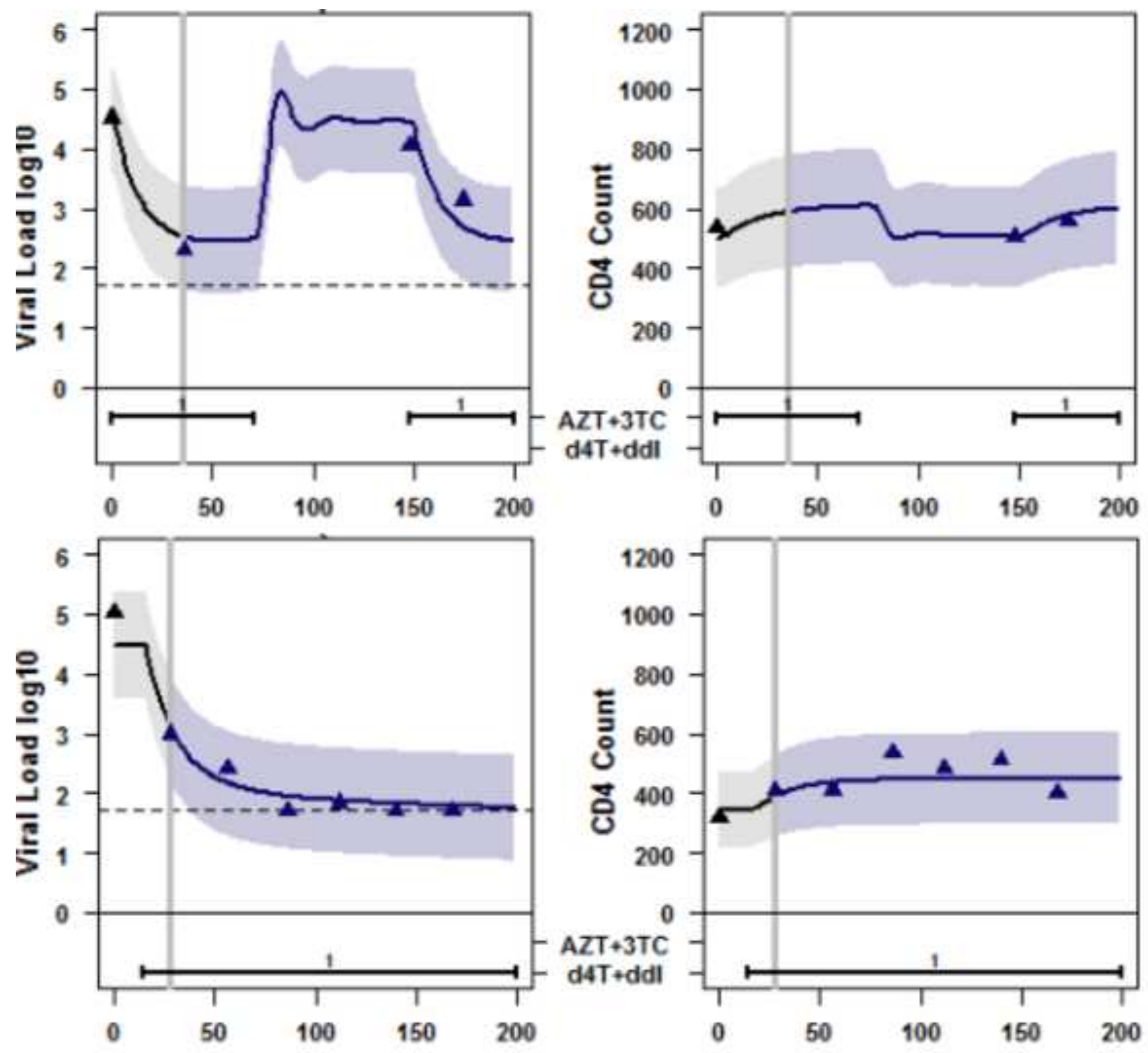

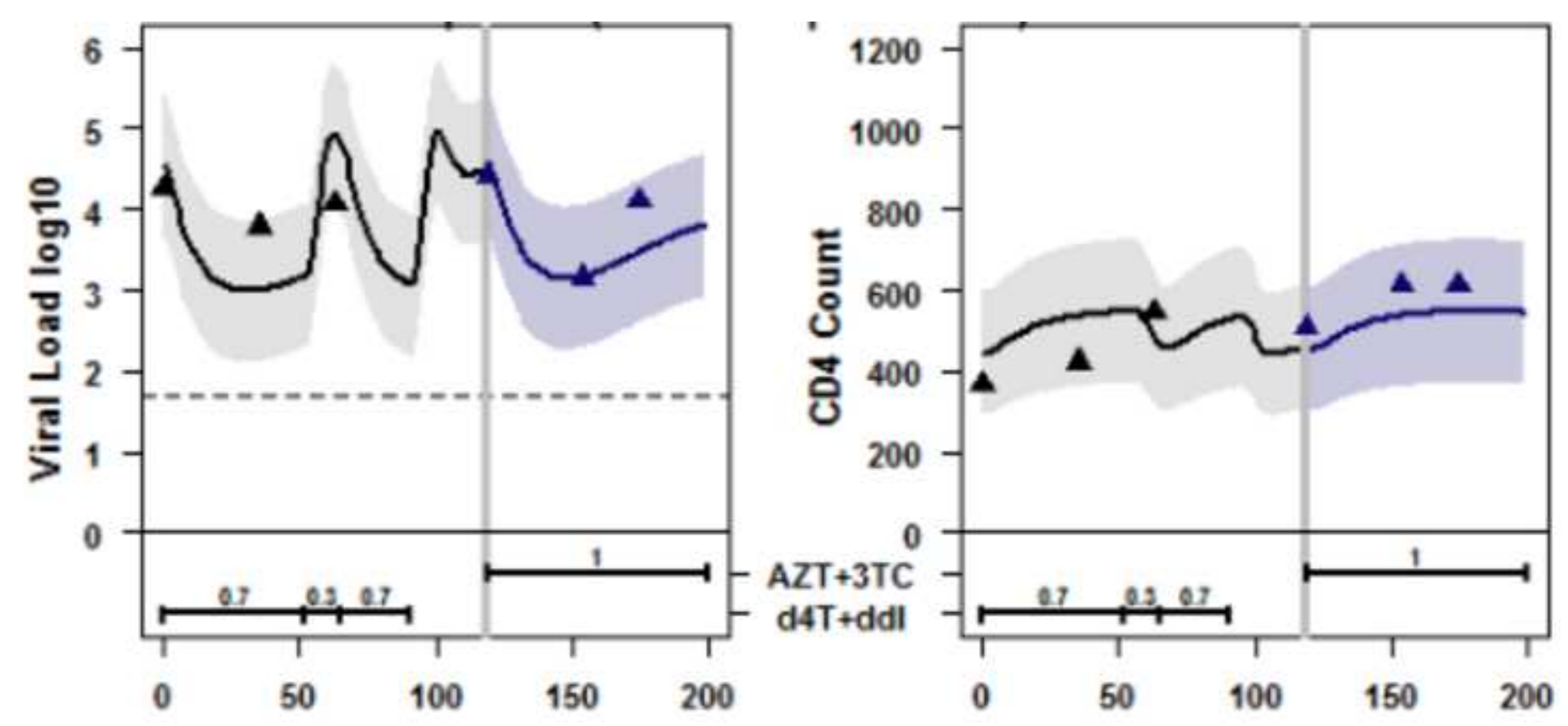
Table 1 - Biological parameters for the "Activated T-cells model".

\begin{tabular}{ll}
\hline Parameter & Meaning \\
\hline $\boldsymbol{\alpha}$ & Activation rate of Q cells $\left(\right.$ day $\left.^{-1}\right)$ \\
$\boldsymbol{\mu}_{\mathbf{T}^{*}}$ & Death rate of T ${ }^{*}$ cells $\left(\right.$ day $\left.^{-1}\right)$ \\
$\boldsymbol{\lambda}$ & Rate of Q cells production $\left(\mu \mathrm{L}^{-1}\right.$ day $\left.^{-1}\right)$ \\
$\boldsymbol{\mu}_{\mathbf{T}}$ & Death rate of T cells $\left(\right.$ day $\left.^{-1}\right)$ \\
$\boldsymbol{\pi}$ & Rate of virions per T $\mathrm{T}^{*}$ cell $\left(\right.$ day $\left.^{-1}\right)$ \\
$\boldsymbol{\rho}$ & Rate of reversion to the Q state $\left(\right.$ day $\left.^{-1}\right)$ \\
$\boldsymbol{\gamma}$ & Infectivity : Infection rate of T cells per virion $\left(\mu \mathrm{L} \mathrm{day}{ }^{-1}\right)$ \\
$\boldsymbol{\mu}_{\mathbf{Q}}$ & Death rate of Q cells $\left(\right.$ day $\left.^{-1}\right)$ \\
$\boldsymbol{\mu}_{\mathbf{V}}$ & Death rate of free virions $\left(\right.$ day $\left.^{-1}\right)$ \\
\hline
\end{tabular}


Table 2 - PK-PD indicators definition.

\begin{tabular}{|c|c|c|c|}
\hline $\begin{array}{l}\text { PK-PD } \\
\text { markers }\end{array}$ & Meaning & Advantages & Drawbacks \\
\hline$C_{\text {through }}$ & $\begin{array}{l}\text { Plasma Drug concentration observed after a drug } \\
\text { administration and just prior to the administration } \\
\text { of a subsequent dose. }\end{array}$ & $\begin{array}{l}\text { * Easy to sample, } \\
\text { * Recognized as a standard measure. }\end{array}$ & $\begin{array}{l}\text { * Spatiotemporal, } \\
\text { * Few data, } \\
\text { * Inter individual variations. }\end{array}$ \\
\hline $\mathrm{IC}_{50}$ & $\begin{array}{l}\text { Drug concentration needed to obtain } 50 \% \\
\text { inhibition of the HIV replication in culture cells. }\end{array}$ & $\begin{array}{l}\text { * Intuitive interpretation - considered as the } \\
\text { minimum required level, } \\
\text { * Can quantify phenotypic resistances. }\end{array}$ & $\begin{array}{l}\text { * In vivo determination is difficult, } \\
\text { * Depend on the virus strains. }\end{array}$ \\
\hline IQ & $\begin{array}{l}C_{\text {through }} / \mathrm{IC}_{50} \\
\text { The Inhibitory Quotient measures how much the } \\
\text { drug exceeds the } \mathrm{IC}_{50} \text {. }\end{array}$ & $\begin{array}{l}\text { * Include virus susceptibility and individual } \\
\text { drug absorption information. }\end{array}$ & $\begin{array}{l}\text { * Based on in vitro results, } \\
\text { * Not optimal in case of mutations, } \\
\text { * Assume linear impact of the dose. }\end{array}$ \\
\hline $\mathbf{v P}$ & $\begin{array}{l}\text { The Virtual Phenotype is the change-fold in } \mathrm{IC}_{50} \\
\text { for a mutant variant compared to a WT. }\end{array}$ & $\begin{array}{l}\text { * Evaluate individual virus susceptibility, } \\
\text { * Account for a mixture of HIV variants. }\end{array}$ & $\begin{array}{l}* \text { Based on in vitro results, } \\
* \text { High costs and long to run. }\end{array}$ \\
\hline vG & $\begin{array}{l}\text { The Virtual Genotype is number of expressed } \\
\text { listed mutations linked to the considered drug. }\end{array}$ & $\begin{array}{l}\text { * Evaluate individual virus genotype, } \\
\text { * Fast to run. }\end{array}$ & $\begin{array}{l}\text { * Need a full understanding and knowledge } \\
\text { of virus position of mutations. }\end{array}$ \\
\hline vIQ & $\begin{array}{l}\text { IQ/vP } \\
\text { The Phenotypic Inhibitory Quotient is the IQ for a } \\
\text { specific virus strain compared to WT. }\end{array}$ & $\begin{array}{l}\text { * Easy to interpret for a clinician, } \\
\text { * No understanding of mutations effects. }\end{array}$ & $\begin{array}{l}\text { * Related with the drugs cut-off, } \\
\text { * Low sensitivity to emerging strains. }\end{array}$ \\
\hline gIQ & $\begin{array}{l}C_{\text {through }} / \mathrm{vG} \\
\text { The Genotypic Inhibitory Quotient evaluates the } \\
\text { effective concentration of the drug. }\end{array}$ & $\begin{array}{l}* \text { Avoid use of } \mathrm{IC}_{50} \\
* \text { Sensitive to detect new resistances. }\end{array}$ & $\begin{array}{l}\text { * Values difficult to interpret, } \\
\text { * Need to understand gene pathways due to } \\
\text { mutations. }\end{array}$ \\
\hline$D$ & $\begin{array}{l}\text { Drug concentration achieved with a standard } \\
\text { dosing. }\end{array}$ & * Dynamic modeling of drug intake. & $\begin{array}{l}\text { * Spatiotemporal Variations, } \\
\text { * Difficult to establish which dose is of } \\
\text { interest (oral, plasma, intracellular ...). }\end{array}$ \\
\hline IIP & $\begin{array}{l}\log _{10}\left(1+\left(D / \mathrm{IC}_{50}\right)^{m}\right) \\
\text { Instantaneous Inhibitory potential measures the } \\
\text { antiviral activity accounting for the slope of the } \\
\text { inhibition curve ( } m \text {, the Hill coefficient) } \\
\text { depending on the dose. }\end{array}$ & $\begin{array}{l}\text { * Interpretation regarding the replication, } \\
\text { * Possible to account for cooperation } \\
\text { between drugs, } \\
\text { * Differentiate antiretroviral agents classes } \\
\text { with } m \text {. }\end{array}$ & $\begin{array}{l}\text { * It is unclear whether it is better than IQ in } \\
\text { vivo to correlate with virologic outcomes } \\
\text { ((Henrich et al., 2010; McMahon et al., } \\
2009)) \text {. }\end{array}$ \\
\hline
\end{tabular}


